UNIVERSIDADE DE BRASÍLIA FACULDADE DE TECNOLOGIA DEPARTAMENTO DE ENGENHARIA FLORESTAL

PROGRAMA DE PÓS-GRADUAÇÃO EM CIÊNCIAS FLORESTAIS

MODELAGEM DO CRESCIMENTO E PRODUÇÃO DE POVOAMENTOS DE Eucalyptus POR DIFERENTES MÉTODOS DE CLASSIFICAÇÃO DE ÍNDICE DE LOCAL

ANDRÉ BARRETO CUNHA

BRASÍLIA - DF

2016 
UNIVERSIDADE DE BRASÍLIA

FACULDADE DE TECNOLOGIA

DEPARTAMENTO DE ENGENHARIA FLORESTAL

PROGRAMA DE PÓS-GRADUAÇÃO EM CIÊNCIAS FLORESTAIS

\title{
MODELAGEM DO CRESCIMENTO E PRODUÇÃO DE POVOAMENTOS DE EucalyptusPOR DIFERENTES MÉTODOS DE CLASSIFICAÇÃO DE ÍNDICE DE LOCAL
}

\author{
ANDRÉ BARRETO CUNHA
}

DISSERTAÇÃO DE MESTRADO SUBMETIDA AO DEPARTAMENTO DE ENGENHARIA FLORESTAL DA FACULDADE DE TECNOLOGIA DA UNIVERSIDADE DE BRASÍLIA, COMO PARTE DOS REQUISITOS NECESSÁRIOS À OBTENÇÃO DO GRAU DE MESTRE EM CIÊNCIAS FLORESTAIS.

APROVADO POR:

Prof. Dr. RENATO VINÍCIUS OLIVEIRA CASTRO

(Departamento de Ciências Agrárias - UFSJ)

(ORIENTADOR)

Prof. Dr. CARLOS ALBERTO ARAÚJO JÚNIOR

(Instituto de Ciências Agrárias - UFMG)

(EXAMINADOR EXTERNO)

Prof. Dr. RICARDO DE OLIVEIRA GASPAR

(Departamento de Engenharia Florestal - UnB)

(EXAMINADOR INTERNO)

Prof. Dr. MAURO ELOI NAPPO

(Departamento de Engenharia Florestal - UnB)

(EXAMINADOR INTERNO)

Brasília, 23 de setembrode 2016 


\section{FICHA CATALOGRÁFICA}

Ficha catalográfica elaborada automaticamente, com os dados fornecidos pelo(a) autor(a)

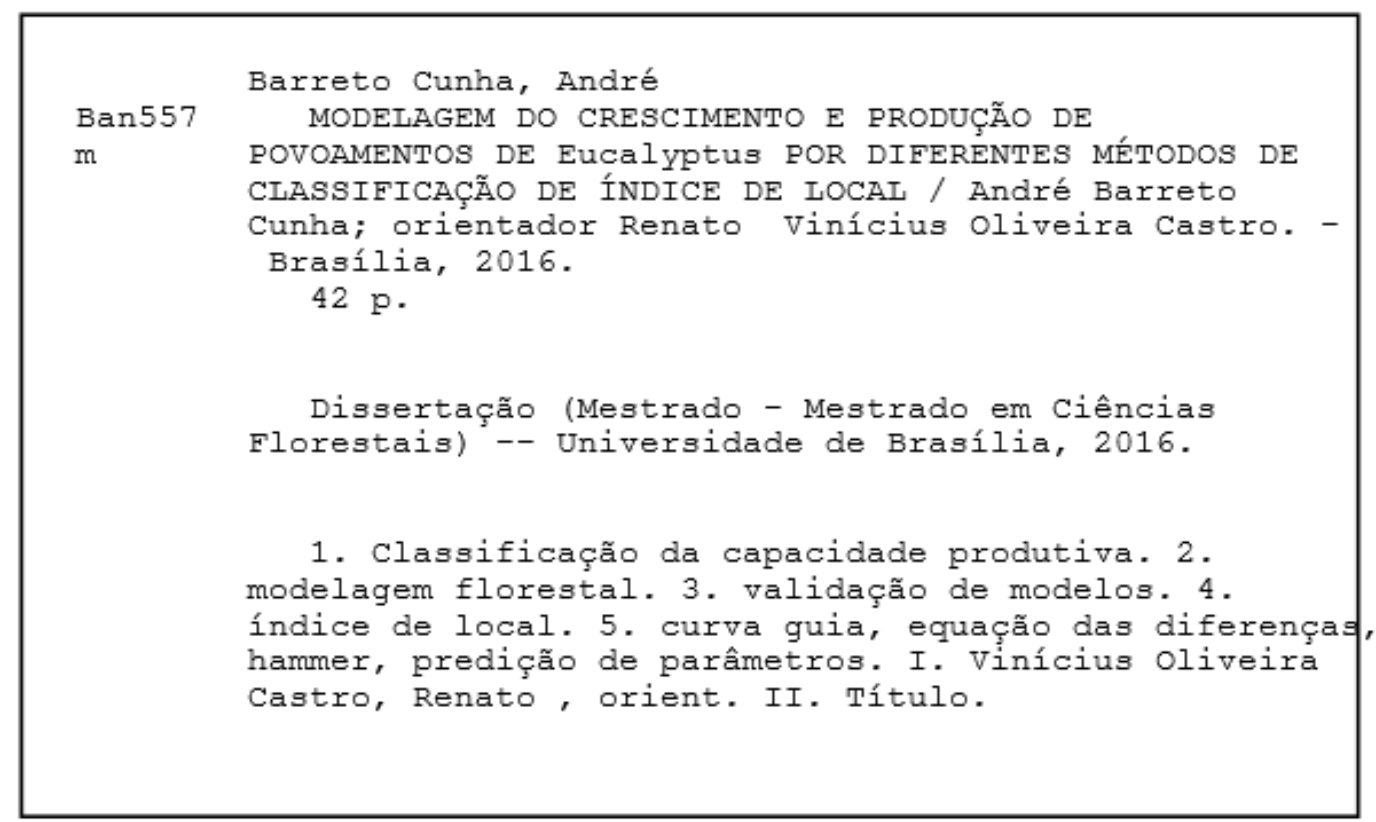

\section{REFERÊNCIA BIBLIOGRÁFICA}

CUNHA,A.B. Modelagem do crescimento e produção de povoamentos de Eucalyptus por diferentes métodos de classificação de índice de local.2016. 52 f.Dissertação de Mestrado em Ciências Florestais.Departamento de Engenharia Florestal, Universidade de Brasília, Brasília, DF.

\section{CESSÃO DE DIREITOS}

AUTOR: André Barreto Cunha

TÍTULO: Modelagem do crescimento e produção de povoamentos de Eucalyptus por diferentes métodos de classificação de índice de local.
GRAU: Mestre
ANO: 2016

É concedido à Universidade de Brasília permissão para reproduzir cópias desta dissertação de mestrado e para emprestar ou vender tais cópias somente para propósitos acadêmicos e científicos. O autor reserva outros direitos de publicação e nenhuma parte desta dissertação de mestrado pode ser reproduzida sem autorização por escrito do autor.

André Barreto Cunha

andre.florestal.unb@hotmail.com 
Dedico

A Deus este trabalho e todas as demais realizações alcançadas em minha vida. Aos meus pais pelo suporte que sempre me deram. Aos amigos e familiares pelas palavras de incentivo e encorajamento. Ao meu orientador que foi fundamental nesta conquista. 


\section{AGRADECIMENTOS}

Agradeço a DEUS por me proporcionar tantas alegrias e oportunidades na vida.

Aos meus familiares que são a essência e a gênesis do que sou e das minhas realizações, sempre me incentivando e me dando forças nos momentos de fraqueza.

Aos amigos que tiveram paciência e me apoiaram nesta luta.

Ao amigo Lindex pelo companheirismo e ajuda nas traduções.

Ao colega de trabalho, Eduardo Krammer que me deu grande apoio em momentos decisivos.

Ao Banco do Brasil, empresa na qual trabalho, pelas horas de trabalho abonadas para que eu pudesse desenvolver esta pesquisa.

Ao meu orientador, professor Dr. Renato Castro, pela oportunidade, paciência e excelente orientação, me apoiando nos momentos de desânimo e me ajudando sempre que foi preciso.

A empresa CENIBRA - Companhia Nipo Brasileira e a Engenheira Florestal, Dr ${ }^{\mathrm{a}}$. Aline Mazon pela cessão dos dados utilizados nesta pesquisa.

Aos professores do departamento de Engenharia Florestal da Universidade de Brasília do curso de mestrado em Ciências Florestais. Aos profissionais do Programa de PósGraduação pelo companheirismo durante os anos de mestrado.

As palavras de carinho e apoio advindas da doce Clarice Abreu, meu chamego.

Enfim, a todos que contribuíram direta ou indiretamente para a realização desta pesquisa. 


\section{EPÍGRAFE}

"Sempre que puder, fale de amor e com amor para alguém. Faz bem aos ouvidos de quem ouve e à alma de quem fala.”.

Irmã Dulce

"O seu mundo é do tamanho do seu sonho." Augusto Curi 


\title{
RESUMO
}

\section{MODELAGEM DO CRESCIMENTO E PRODUÇÃO DE POVOAMENTOS DE Eucalyptus POR DIFERENTES MÉTODOS DE CLASSIFICAÇÃO DE ÍNDICE DE LOCAL}

\author{
Autor: André Barreto Cunha \\ Orientador: Prof. Dr. Renato Vinícius Oliveira Castro \\ Programa de Pós-graduação em Ciências Florestais \\ Brasília, 23 desetembro de 2016
}

Com o objetivo de verificar a eficiência de quatro métodos de classificação de índice de local na modelagem do crescimento e da produção florestal em nível de povoamento total em plantios de Eucalyptusspp., este trabalho foi realizado utilizando-se de dados fornecidos por uma empresa florestal com plantio de 83.420 hectares situadosem diferentes municípios do estado deMinas Gerais-MG, localizados ao Norte, Centro e Sul do estado.Foram utilizados dados provenientes de 1.643 (um mil seiscentos e quarenta e três) parcelas permanentes provenientes de inventário florestal contínuo (IFC) com pelo menos três remedições cada, de povoamentos de clones híbridos de Eucalyptusspp.não desbastados, com idades variando de 17 a 114 meses, medidos entre os anos de 2006 a 2013. As parcelas foram divididas em duas partes, uma contendo $70 \%$, totalizando 1.150 (mil cento e cinquenta) parcelas, a qual chamou-se de dados para "ajuste" e outra parte, contendo os 30\% restante, correspondente a 493 (quatrocentos e noventa e três) parcelas, a qual chamou-se de dados para "validação". A classificação da capacidade produtiva de cada parcela foi feita por meio de curvas de índices de local, empregando-se os métodos da Curva Guia, da Equação das Diferenças, de Hammer e da Predição de Parâmetros. Em seguida, o primeiro conjunto de dados foi utilizado para ajustar os sistemas de equações simultâneas de Clutter, alternando o uso da variável " $S$ " dos quatro métodos de classificação de local avaliados. Ajustou-se ainda um sistema de equações sem a variável site. Os modelos testados foram avaliados com as estatísticas: significância dos parâmetros das equações $(\alpha=0,05)$, erro padrão da estimativa percentual $(S y x \%)$, coeficiente de determinação ajustado ( $\left.R^{2} a j u s t\right)$ e distribuição gráfica dos resíduos.A validação foi feita aplicando o sistema de equações aos 30\% das parcelas separadas para isso. Para tanto, a partir dos dados de medição realizada em uma primeira ocasião, fez-se a projeção para a idade seguinte e, assim, sucessivamente até a última idade mensurada de cada parcela. Em seguida, os valores estimados foram comparados aos valores observados. Os resultados demonstraram que a classificação da capacidade produtiva por meio de índices de local foi eficiente pelos quatro métodos avaliados e os modelos de Clutter ajustados utilizando as variáveis $S$ por todos os métodos foram precisos. Não foi observada diferença entre as prognoses realizadas pelas diferentes equações, originadas pelos diferentes métodos de classificação do índice de local, entretanto, a exclusão da variável " $S$ " no modelo de prognose comprometeu as estimativas de produção. Os métodos da Curva Guia eda Equação da Diferenças mostraram-se menos complexos na sua aplicação, sendo recomendados para a prognose do povoamento avaliado.

Palavras chave:classificação da capacidade produtiva, modelagem florestal, validação de modelos, índice de local. 


\section{SUMÁRIO}

1 INTRODUÇÃ

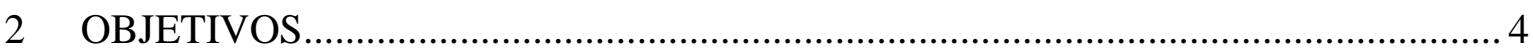

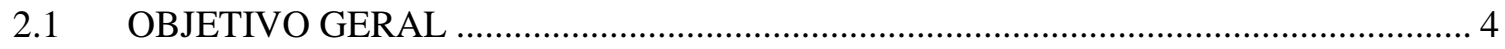

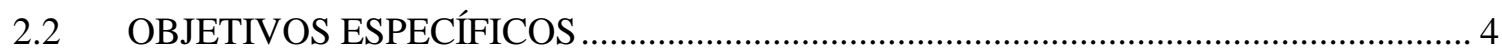

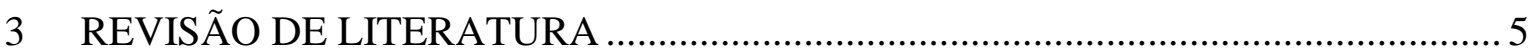

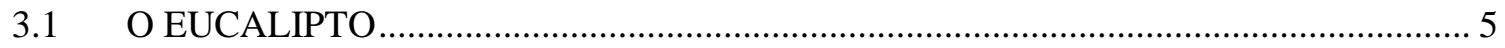

3.2 MÉTODOS DE DETERMINAÇÃO DA QUALIDADE DO LOCAL ............................. 7

3.3 MÉTODOS PARA A CONSTRUÇÃO DAS CURVAS DE ÍNDICE DE LOCAL ........ 12

3.4 MODELAGEM DO CRESCIMENTO E DA PRODUÇÃO ………….......................... 13

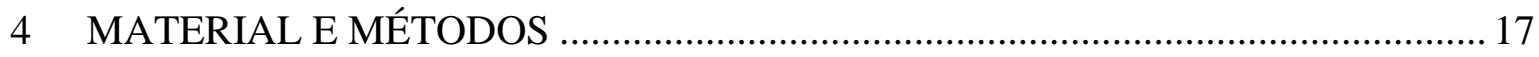

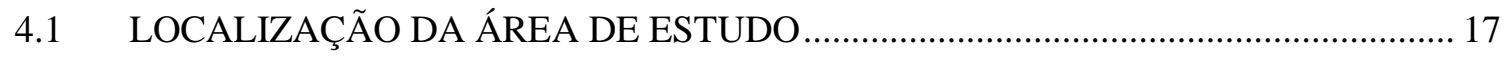

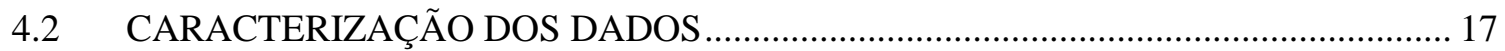

4.3 MODELAGEM DE CURVAS DE ÍNDICE DE LOCAL ........................................... 18

4.4 MODELAGEM DO CRESCIMENTO E DA PRODUÇÃO EM NÍVEL DE

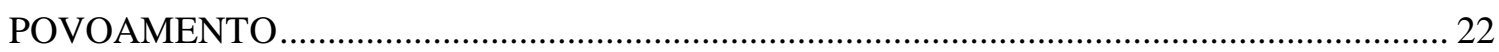

4.4.1 Estatísticas de avaliação do sistema de Clutter ……………………………............ 23

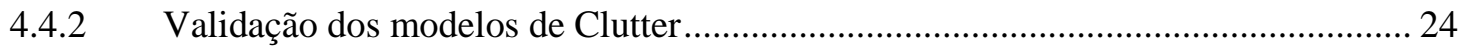

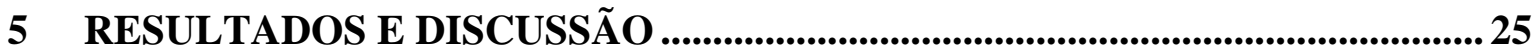

5.1 MODELAGEM DE CURVAS DE ÍNDICE DE LOCAL .............................................. 25

5.2 MODELAGEM DO CRESCIMENTO E DA PRODUÇÃO EM NÍVEL DE

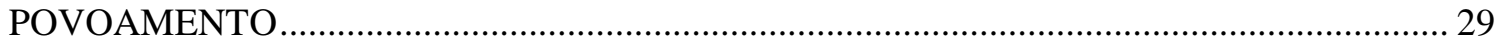

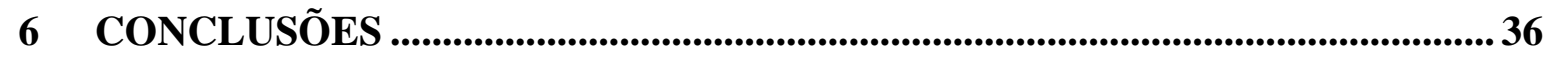

REFERENCIAS BIBLIOGRÁFICAS .................................................................... 37 


\section{LISTA DE FIGURAS}

Figura 1 - Gráfico de estabelecimento da ITC (Idade Técnica de Corte). O ponto de cruzamento do IMM (Incremento Médio Mensal) e do ICM (Incremento Corrente Mensal) acontecendo aos 71 meses.

Figura 2 - Classificação da capacidade produtiva pelos quatro métodos avaliados utilizando-se os dados separados para ajuste do modelo de Clutter. 27 Figura 3 - Análise gráfica das correlações e dos resíduos percentuais obtidos dos modelos de Clutter ajustados utilizando-se a variável site classificada pelos métodos da Curva Guia em a); da Equação das Diferenças em b); de Hammer em c); da Predição de Parâmetros em d) e sem a variável site em e).

Figura 4 - Tendência média de erros para cada classe de produtividade, por projeção, para cada método estudado, utilizando ou não índice de local, dos dados de validação. 


\section{LISTA DE TABELAS}

Tabela 1: Amplitude e valores de idade, média da Altura Dominante $(H d)$, Área Basal e Volume com casca de toda a população estudada.......................................................... 18 Tabela 2 - Percentual de igualdade de classificação da capacidade produtiva entre os métodos avaliados utilizando os dados separados para ajuste. 28 Tabela 3 -Resultado das estatísticas de precisão para o ajuste dos modelos de Clutter variando o $(S)$ obtido pelos quatro métodos estudados: Curva Guia (C.G.); Equação das Diferenças (E.D.); Hammer, Predição de Parâmetros (P.P) e Sem a Variável Site (SS) .... 30 


\section{INTRODUÇÃO}

Entre asflorestas equiâneas, as de Eucalipto são as mais plantadas e estudadas no Brasil (VITAL, 2007).

O setor de árvores plantadas reúne uma gama de empresas, investidores e empreendedores que atuam desde o fornecimento de insumos e máquinas específicas para a atividade florestal, passando pela prestação de serviços especializados, como a produção e plantio de mudas, colheita de árvores e transporte de madeira, até a transformação da madeira em bens intermediários e finais (IBÁ, 2015).

Os povoamentos equiâneos têm sido utilizados como fontes alternativas de produção de madeira e derivados, diminuindo a pressão sobre as florestas mistas inequiâneas. Apesar da possibilidade de uso da madeira de povoamentos de eucalipto para multiprodutos, a maior parte da madeira ainda é utilizada em fábricas de celulose e empresas produtoras de carvão vegetal (ALCÂNTARA, 2012).

As estimativas da produtividade de um determinado local são elementos fundamentais para o manejo destas florestas, pois contribuem para a determinação da colheita anual, do período de rotação e da escolha de espécies adequadas (VARGAS-LARRETA et al., 2010).

Para a elaboração de planos de manejo são necessárias informações referentes à floresta, uma avaliação do estoque atual e a produtividade do estoque em crescimento, assim como sua produção esperada. De posse do conhecimento de seu estoque e produtividade, é possível planejar o abastecimento de indústrias de base florestais, calcular o que se pode retirar da floresta anualmente, ou periodicamente, para que esta não seja conduzida à exaustão de seus recursos ou, até mesmo, a uma superestocagem se, por acaso, for feito o corte de uma quantia inferior do que o seu crescimento em sucessivos períodos, podendo a floresta ficar estagnada (FIGUEIREDO, 2005).

A classificação de uma floresta em relação à sua produtividade é de grande importância, pois está relacionada: com diferentes respostas das espécies, híbridos e clones, que influem 
diretamente sobre a viabilidade de empreendimentos florestais; com a pesquisa ecológica, visando estudos de luminosidade, biomassa e exportação de nutrientes nas diversas fases de crescimento; com as dimensões dos produtos em diferentes idades; na adoção de técnicas de manejo e conservação do solo e no planejamento da produção, por meio da determinação da idade ótima e econômica de corte (TONINI et al., 2002).

Há vários métodos descritos para proceder à classificação da capacidade produtiva de sítios florestais, entretanto, a altura dominante correlacionada com a idade tem sido considerado o método mais prático e usual (SELLE et al., 2008), uma vez que esta variável representa a resposta aos fatores ambientais inter-relacionados e não sofre significativa influência dos tratamentos silviculturais e da competição (TONINI et al., 2002).

Parece haver consenso entre vários autores (SPURR, 1952; VAN LAAR, 1997; DEVAN e BURKHART, 1982; STOUT e SHUMWAY, 1982) de que a altura dominante das árvores, apesar das falhas que pode apresentar, é atualmente o melhor índice para representar aqualidade de sítio. Dessa forma, o índice de local é quase invariavelmente apresentado como a altura das árvores dominantes e codominantes de um povoamento numa determinada idade, sob mesmos espaçamentos e tratos silviculturais, a qual é chamada de idade índice.Essa idade índice, também chamada de idade técnica de colheita, é aquela em que o incremento médio (IM) é máximo, e, nesta idade, este incremento é igual ao incremento corrente (IC), ou seja, IM=IC (CAMPOS e LEITE, 2013).

A altura dominante segundo Assmann (1970) é muito utilizada para indicar a capacidade do local. Trata-se da altura média das 100 árvores mais grossas por hectare, que em outras palavras, refere-se à altura de uma árvore dominante a cada $100 \mathrm{~m}^{2}$ de área amostral. As árvores são identificadas como dominantes na primeira ocasião da medição das parcelas e os critérios utilizados para a qualificação dessa dominância são características de sanidade, ausência de bifurcação, tortuosidade e danos, e copa situada no dossel superior recebendo radiação solar direta. O seu uso na classificação justifica-se por possuir alta correlação com a produtividade total (HAGGLUND, 1981).

O índice de local é uma variável numérica que procura quantificar a qualidade do local por meio de parâmetros dendrométricos e de povoamento (volume de madeira, altura das árvores, área basal e outros) (BATISTA e DO COUTO, 1986). Segundo Cajander (1926), 
Huber em 1824, utilizou pela primeira vez o índice de local na Alemanha. Esse conceito foi discutido em uma série de artigos (ROTH, 1916, 1918; SPRING, 1917; BATES, 1918 e FROTHINGHAM, 1918) que compararam com a relação volume-idade, plantas indicadoras e fatores ambientais como possíveis índices de local alternativos, chegando-se a conclusão que a relação altura-idade tem maior correlação com a produtividade do que as demais.

Diversos métodos de classificação de local foram desenvolvidos, dentre eles, o método da construção de curvas de índice de local, que permite uma classificação baseada na análise quantitativa da influência ambiental (IPEF, 2014).As curvas de índice de local constituemse atualmente no método mais prático e difundido para classificar a produtividade florestal, uma vez que utiliza a variável (altura dominante) relacionada com a idade do povoamento, sendo altamente correlacionada com a produção volumétrica (TAQUETTI, 2014).

Percebe-se a necessidade de estudos sobre a dinâmica do crescimento de povoamentos comerciais, visando o aprimoramento da modelagem do crescimento e da produção, para proporcionar aos manejadores informações mais precisas sobre a época correta de colheita, além de fornecer informações sobre a adequação de espécie e/ou procedências para determinadas localidades, entre outros (DEMOLINARI, 2007).

Considerando o exposto, o presente trabalho avaliou a eficiência e a aplicabilidade de quatro diferentes métodos de classificação da capacidade produtiva do solo (Curva-guia, Equação das Diferenças, Hammer e Predição de Parâmetros), por meio do índice de local $(S)$ e o uso desseíndice como variável independente no modelo de projeção do crescimento e produção de Clutter (1983), em nível de povoamento total, para plantios comerciais de eucalipto não desbastados. 


\section{OBJETIVOS}

\subsection{OBJETIVO GERAL}

Comparar a eficiência de quatro diferentes métodos de classificação de índice de local na modelagem do crescimento e da produção florestal em nível de povoamento total em plantios comerciais não desbastados de Eucalyptus spp.

\subsection{OBJETIVOS ESPECÍFICOS}

- Classificar ossítios pelosseguintes métodos: Curva Guia, Equação das Diferenças, Hammer e Predição de Parâmetros;

- Ajustar modelos de crescimento e produção em nível de povoamento (Modelo de Clutter) utilizando índices de local estimados pelosquatro diferentes métodos;

- Verificar e avaliar a resposta de cada método de classificação de local em relação ao modelo de projeção de volume. Comparar os resultados obtidos pelo uso dos quatro métodos a um modelo de prognose sem a variável site. 


\section{REVISÃO DE LITERATURA}

\subsection{O EUCALIPTO}

O gênero Eucalyptus está incluído na família Myrtaceae e possui mais de 700 espécies, a maioria delas nativas da Austrália. A partir dos anos 1970, alguns estudos apontaram que o gênero Eucalyptus não era um agrupamento taxonômico natural, apresentando duas diferentes linhagens, a primeira incluindo os até então subgêneros Angophora e Corymbia, e a outra compreendendo o subgênero Eucalyptus. Nos anos 1990, o gênero Eucalyptus foi reagrupado, fazendo com que os gêneros Angophora e Corymbia fossem criados. O gênero Corymbia possui 113 espécies, as quais possuem madeira com alta densidade básica, altos teores de extrativos e carboidratos, além de baixa proporção de lignina. Essas espécies apresentam importância comercial principalmente para a extração de óleos essenciais de suas folhas e utilização da madeira na construção civil, para a produção de carvão vegetal e geração de energia (SEGURA, 2015).

Originário da Austrália, o eucalipto foi introduzido no Brasil em 1904, sendo hoje uma das essências florestais que mais têm atendido às necessidades de reposição de matéria-prima no processo industrial, principalmente do setor de papel e celulose (DOSSA et al., 2003; IPEF, 2014).

O eucaliptoé plantado na maioria das regiões de clima tropical e subtropical do mundo, entre as latitudes de $40^{\circ} \mathrm{N}$ e $45^{\circ} \mathrm{S}$, já que possui espécies adaptadas a diversas condições de clima e solo. Brasil, Índia, África do Sul, Portugal, Angola, Espanha e China são os maiores produtores mundiais de eucalipto(GONZÁLEZ, 2002).

Os plantios de eucalipto ocupam 5,6 milhões de hectares da área de árvores plantadas do País e estão localizados, principalmente, em Minas Gerais (24\%), em São Paulo (17\%) e no Mato Grosso do Sul (15\%) (IBÁ, 2016).

As florestas plantadas brasileiras atingiram, nos últimos anos, altos níveis de produtividade, com destaque para as florestas de eucalipto, que alcançam incrementos de madeira superiores a $35 \mathrm{~m} / \mathrm{ha}^{-1} \cdot \mathrm{ano}^{-1}$. A alta produtividade dessas florestas no Brasil se deve a diversos fatores, dentre os quais estão as condições edafoclimáticas do país, 
favoráveis ao crescimento de inúmeras espécies deste gênero, as avançadas técnicas de manejo silvicultural aplicadas e, principalmente, aos programas de melhoramento genético, bastante desenvolvidos para este gênero (SEGURA, 2015).

As espécies do gênero Eucalyptus, devido ao seu rápido crescimento e produção demadeira, aliado à sua grande diversidade genéticaentre as espécies e adaptabilidade a diferentesregiões, ocupam posição de destaque no setor florestal mundial (MARTINS, 2002).

Os principais motivos para a escolha de espécies de eucalipto para implantação de florestas de produção são o rápido crescimento das espécies, fornecendo madeira em um curto espaço de tempo, e também a grande variedade de usos para os quais a madeira pode ser aproveitada (SILVA, 2005).

Segundo Ferreira (2003), o eucalipto apresenta grande importância pela possibilidade de uso múltiplo, podendo atender a todos os segmentos de celulose, madeira sólida, carvão vegetal e energia, principalmente para celulose e energia onde historicamente deu contribuição especial. A escolha da espécie vai depender, principalmente, do clima da área a ser plantada e das características físicas e químicas do solo, além do destino da madeira produzida (SCAVINSK, 2014).

A possibilidade de uso da madeira de eucalipto para diversos fins tem estimulado a implantação de florestas de uso múltiplo. Dessa forma, muitos estudos estão sendo realizados para melhor se aproveitar o potencial econômico da floresta, destacando-se melhoramento de material genético e manejo silvicultural (teste de espaçamentos, idade de corte e técnicas silviculturais). De modo geral, com o uso múltiplo, pretendem-se obter de uma área implantada, variados tipos de produtos, ou seja, diferentes finalidades para uma mesma floresta (IPEF, 2014).

Além do aumento da área plantada, esforços têm sido realizados por diversos órgãos governamentais e não governamentais em pesquisas voltadas ao melhoramento, à nutrição e ao manejo florestal de plantios de eucalipto (KALLARACKAL e SOMER, 1997; STAPE, 1995). Não obstante, a necessidade de conhecimento da produção do plantio tem incentivado as pesquisas na área de prognose do crescimento e produção florestal. 


\subsection{MÉTODOS DE DETERMINAÇÃO DA QUALIDADE DO LOCAL}

A qualidade do local é uma variável que resume o efeito das variáveis ambientais, expressando o potencial de produção da área(CAMPOS e LEITE, 2013). Os ecologistas definem o sítio como sendo uma unidade geográfica uniforme distinguida pela combinação de características do meio. Para os silvicultores, o sítio corresponde a um fator primário de produção com determinada capacidade de produzir madeira ou outros produtos florestais (SCHONAU, 1987).

Spurr (1952) definiu um sítio florestal por meio de fatores climáticos e edáficos, e por esse motivo salientou que quanto mais destes fatores forem usados como indicadores da produtividade, melhor será a correlação.

Existem diversos fatores considerados na classificação de local, como o tipo de solo, precipitação, cobertura vegetal, topografia e relevo, composição de espécies, classe de idade, espaçamento inicial e regime de corte de cada compartimento da floresta (CAMPOS e LEITE, 2013).

A capacidade produtiva ou sítio $(S)$ juntamente com a idade $(I)$ e o grau de utilização do local (ind. $h a^{-1}$ ) são os fatores do qual o crescimento e a produção de um povoamento florestal dependem (CAMPOS e LEITE, 2013), e a interação desses fatores, integrados com o meio ambiente sobre a planta, expressa a qualidade do local, sendo que as condições de crescimento são boas em sítios bons e vice-versa (MIGUEL et al., 2011).

Os principais objetivos da avaliação da qualidade dos locais são: a) estimativa do rendimento global dos povoamentos; b) planejamento e execução de trabalhos de pesquisa; c) programação e execução dos trabalhos de manutenção das plantações existentes (tratos silviculturais); d) extensão da classificação da qualidade do local em áreas a serem plantadas, para a seleção adequada de espécies (SCHNEIDER, 2008).

Portanto, a determinação da produtividade dos sítios florestais é fator básico, na condução de povoamentos e no planejamento da produção madeireira de uma empresa florestal (SCAVINSKI, 2014). 
São várias as alternativas para efetuar a classificação da qualidade do local.Para Clutter et al. (1983), os métodos para estimar a qualidade do local podem ser classificados em diretos e indiretos. Os métodos indiretos avaliam a qualidade do local a partir de atributos do ambiente, levando em consideração características como o clima, solo e vegetação e podem ser divididos em: quantitativos, também conhecido como análise fator-sítio ou solo, e qualitativos, que envolvem a divisão das terras em unidades com características e potencial de produção e de uso uniformes (SCHÖNAU, 1987).

Os diretos, por sua vez, utilizam-se de indicadores na própria vegetação (elementos dendrométricos e do povoamento), que refletem as interações de todos os fatores do ambiente no próprio sítio para aquela vegetação (CLUTTER et al., 1983).

Para quantificar a capacidade produtiva de povoamentos equiâneos, o método mais usual em manejo florestal é a estimativa de índices de local, calculados em função de dados médios de alturas dominantes e idade das árvores. Esse método tem-se tornado popular, principalmente, porque quantifica a capacidade produtiva do local por meio de uma expressão numérica e não apenas o descreve de forma qualitativa e, portanto, subjetiva (DIAS et al., 2005; CAMPOS e LEITE, 2013). De acordo com Campos e Leite (2013), as principais alternativas de construção de curvas de índices de local são: método da curvaguia; método de atribuição preliminar de índices de local; método da equação das diferenças; método de Hammer; e método de predição de parâmetros. Segundo Dias et al. (2005) o método da curva-guia tem sido amplamente utilizado nos estudos referentes à quantificação da capacidade produtiva de povoamentos florestais de eucalipto. No entanto, poucos estudos têm sido realizados utilizando os outros métodos.

As curvas de índice de local são geradas com equações que relacionam a idade índice e o crescimento em altura das árvores dominantes e codominantes para a determinação do índice local. Sendo a idade índice ou idade de referência geralmente selecionada próxima da idade de colheita (CLUTTER et al., 1983).

Abreu (2000) salientou que os estudos de crescimento e produção utilizam dados de povoamentos como base para a modelagem. Por esse motivo, deve-se utilizar um conjunto de dados consistente, preferencialmente advindos de parcelas permanentes, na definição de 
variáveis que permitam compatibilizar a precisão das estimativas e exequibilidade de aplicação dos modelos de prognose.

Os pares de dados, altura dominante e idade devem abranger todas as variações de crescimento e idade do povoamento que as curvas de índice de local abrangerão (SELLE et al., 2008).Segundo Clutter et al. (1983), os dados utilizados para o desenvolvimento de modelos de índice de local podem ser advindos de: a) Medições de pares de valores (altura dominante, idade) provenientes de parcelas temporárias; b) Medições de pares de valores (altura dominante, idade), em parcelas permanentes; c) Reconstruções do desenvolvimento da altura (altura dominante, idade) em árvores individuais pelo método de análise do tronco completa.

O uso de informações obtidas de parcelas temporárias, embora sejam os mais rápidos para serem coletados e de menor custo, podem levar a sérias tendências se a amostragem não contemplar todos os sítios nas várias idades em questão (CLUTTER et al., 1983).Ainda segundo estes autores, a medição periódica de parcelas permanentes fornece os melhores dados para o desenvolvimento de equações para definição do índice de local. No entanto, este processo de obtenção de dados é bastante moroso (exige o acompanhamento da mesma parcela ao longo do tempo) e dispendioso. Por outro lado, o método de análise do tronco gera dados com qualidade equivalente; embora com custos elevados, os dados podem ser obtidos de forma relativamente rápida. Porém, tem o inconveniente de ser aplicado apenas às espécies que apresentam os anéis de crescimento anuais visíveis e de pressupor que a árvore coletada, foi dominante ao longo de toda a sua vida (SCAVINSK, 2014).

Para a construção de curvas de índices de local, é necessário definir um modelo que represente a relação da altura com a idade, bem como definir o comportamento da família de curvas geradas por esse modelo, que deve ser flexível para gerar curvas com padrão exponencial ou sigmoidal. Isso porque, na maioria das vezes, a relação altura dominante $(H d)$ versus idade (I) segue um desses padrões (BINOTI, 2012). Conforme Campos e Leite (2013), para plantios de eucalipto no Brasil tem sido comum o uso do método da curvaguia com o emprego da relação funcional $\operatorname{LnHd}=f\left(I^{-1}\right)$, ou das funções logística ou Chapman-Richards. No primeiro caso, a relação implícita entre $H d$ e idade é exponencial e nos outros dois, sigmoidal. 
Dependendo da procedência dos dados e do método utilizado, as curvas de índice de local podem ser anamórficas ou polimórficas. As curvas anamórficas apresentam o mesmo comportamento, com amplitude semelhante de uma curva para outra, já as polimórficas apresentam comportamentos diferentes entre si (CAMPOS e LEITE, 2013).

Segundo Campos e Leite (2013), curvas anamórficas são aquelas em que a tendência do crescimento em altura é a mesma em todos os locais, ou seja, em cada idade a distância entre as curvas é idêntica. São curvas com inclinação comum e constante, mas variando o ponto de interseção; elas apresentam mesma forma para todos os índices de local.

As curvas anamórficas apresentam, de acordo com Spurr (1952) e Beck (1971), duas fontes principais de erros:

$1^{\circ}$ - As curvas anamórficas só são precisas quando a amostragem é adequadamente realizada, de forma que a variação do índice de local seja igualmente representada em todas as idades;

$2^{\circ}$ - As curvas anamórficas consideram que a influência da variação do sítio sobre a altura seja uniforme em todas as idades, de modo que a forma das curvas é a mesma para todos os sítios.

Segundo Scolforo e Machado (1988a), o anamorfismo das curvas de local pode ser identificado a partir de:

- Verificação do coeficiente de variação (CV) das alturas médias das árvores dominantes por classe de sítio e idade, já que uma das suposições básicas do anamorfismo é que este valor seja semelhante em todas as idades nas classes de sítio;

- Verificação da existência de relação linear entre índice de local e as alturas dominantes médias nas várias idades consideradas, expressando que o índice de local não depende da idade, mais sim da capacidade produtiva do local.

Bull 1931, citado por DeMars (1969), foi o primeiro a notar o polimorfismo, desenvolvendo em seu trabalho sete curvas de local polimórficas para Pinus resinosa, cada uma baseada em uma porção definida na variação total do sítio, concluindo que as curvas para diferentes índices de local podem assumir diferentes formas. 
As curvas polimórficas representam a forma natural da curva para os diferentes sítios e são geralmente consideradas mais compatíveis com os hábitos de crescimento das árvores (DOLPH, 1991).

As curvas polimórficas podem ser divididas em duas categorias (SCOLFORO, 1997):

- Curvas Polimórficas que não se cruzam (disjuntas): nesta família de curvas a relação de proporcionalidade entre as curvas de índice de local é verificada, entretanto estas curvas não se cruzam dentro da faixa de idade de interesse.

- Curvas Polimórficas que se cruzam (não disjuntas): nesta família de curvas também não existe proporcionalidade no crescimento da altura entre as classes de sítio, entretanto as curvas que expressam o sítio se cruzam dentro da faixa de idade de interesse.

As curvas polimórficas são construídas baseadas em dados de medições repetidas em intervalos de tempos sucessivos (parcelas permanentes), na análise do tronco de espécies com anéis de crescimento visível ou na análise dos verticilos anuais de crescimento das espécies que os apresentam (SPURR, 1952). Segundo Machado (1980), a principal vantagem das curvas polimórficas é que cada curva é desenvolvida a partir de dados obtidos em cada sítio.

Não existe consenso sobre a superioridade quanto ao uso de curvas anamórficas ou polimórficas, isto depende da espécie em questão e da região onde se está estudando (HAHN e CARMEAN, 1982) e de que as vantagens para um tipo de curva se traduzem em desvantagem para o outro e vice-versa (TORRES, 2001).

No Brasil tem predominado o emprego de curvas anamórficas e, entre outros métodos de construção, tem sido mais comum o emprego do método da curva-guia, conforme descrito em Campos e Leite (2013).

Emerenciano (1981) citou que um dos primeiros modelos utilizados para o estudo das curvas de índice de local, foi o de Schumacher (1939). Chagas Campos (1970) utilizou esse modelo para a construção de curvas anamórficas para Pinus elliottii no estado de São Paulo. Também em São Paulo, Couto e Bastos (1986) utilizaram este modelo, porém para Eucalyptus saligna e Eucalyptus grandis. 
O modelo de Prodan (1968) tem sido muito utilizado por pesquisadores florestais em várias partes do mundo por dois fatores: a simplicidade de obtenção dos coeficientes e uso destes para as estimativas das variáveis de interesse; e a precisão que o modelo oferece (MARCOLIN, 1990, citado por TONINI et al. ,2002).

De acordo com Drescher et al.(2001), a análise do crescimento da altura dominante, em função da idade, realizada mediante a equação de Richards, apresenta bons resultados para uma grande variedade de fenômenos biológicos, sendo essa equação também citada na literatura como função de Chapman-Richards.

\subsection{MÉTODOS PARA A CONSTRUÇÃO DAS CURVAS DE ÍNDICE DE LOCAL}

Campos e Leite (2013) citaram como as principais alternativas de construção de curvas de índice de local: a) Método da Curva Guia; b) Método da Equação das Diferenças; c) Método de Hammer e d) Método da Predição de Parâmetros.

Apesar da existência de todos estes métodos, há uma certa predominância por parte dos manejadores florestais na utilização do método da Curva Guia (curvas anamórficas) e do método da Equação das Diferenças (curvas anamórficas ou polimórficas) (CAMPOS e LEITE, 2013). Este fato se deve à fácil aplicabilidade do método e os bons resultados que tem apresentado.

Segundo Scolforo (1997), o método da curva-guia passou a ser utilizado no final da década de 1930, com a introdução das técnicas de regressões lineares múltiplas no meio florestal. Segundo Figueiredo (2005), com base na equação que representa a Curva Guia, uma equação de índices de local é gerada quando se considera a idade $(I)$ do povoamento igual à idade de referência $\left(I_{r e f}\right)$ e a altura dominante igual ao índice de local $\left(H d=S\right.$ e $\left.I=I_{r e f}\right)$. Trabalhando a equação, isola-se $\beta_{0}$ e obtém-se a altura dominante $(H d)$ para cada sítio na idade de referência $\left(I_{r e f}\right)$, obtendo-se dessa forma as curvas anamórficas.

O método da Equação das Diferenças foi proposto inicialmente por Bailey e Clutter (1974), para o desenvolvimento de curvas de índice de local anamórficas ou polimórficas, utilizando dados provenientes somente de parcelas permanentes ou de análise do tronco. 
De acordo com Prodan et al. (1997) o pressuposto básico deste método é que todo par de observações se aplica à mesma relação altura-idade. Dessa forma, empregando pares consecutivos de idade e altura dominante, os modelos são ajustados.

Segundo Campos e Leite (2013), o método Hammer constitui uma variação do método da Curva Guia. Nesse método o parâmetro $\beta_{0}$ do modelo escolhido para estimar a altura dominante é substituído por uma equação, de forma que as curvas de índice de local passem por alturas prefixadas coincidentes com índices de local predefinidos. Os passos principais do método são: a) ajustar a função, obtendo as estimativas $\beta_{0} \mathrm{e} \beta_{1}$; b) fixar índices de local, compatíveis com a variação de altura dominante na idade índice escolhida; c) substituir esses índices na equação inicial no lugar da variável $H d$ e a idade índice no lugar da variável $I$ e obter $\beta_{0}$ para cada índice de local; d) com os pares de dados obtidos no passo anterior $\left(S, \beta_{0}\right)$, ajusta-se a regressão linear simples $\beta_{0}=\alpha_{0}+\left(\alpha_{1} S\right)+\varepsilon$ e substitui-se a equação resultante na equação inicial. Esta equação final será utilizada para construir curvas de índice de local.

O método da Predição de Parâmetros é usado, principalmente, para gerar curvas polimórficas disjuntas (CLUTTER et al., 1983), e para utilização deste método são necessários dados de análise de tronco ou de remedições de parcelas permanentes.Em resumo, este método funciona da seguinte maneira: ajusta-se um modelo que relacione a altura dominante com a idade para cada parcela permanente; substitui-se a idade índice em cada uma das regressões para encontrarum índice de local para cada parcela; relaciona-se cada parâmetro estimado $\left(\beta_{i}\right)$ com os índices de local $(S)$, por regressão linear ou não linear; substitui-se as equações obtidas conforme item anterior no modelo inicial, obtendo a expressão a ser utilizada para construção das curvas de índice de local (CAMPOS e LEITE, 2013).

\subsection{MODELAGEM DO CRESCIMENTO E DA PRODUÇÃO}

Em mensuração florestal, a prognose da produção é obtida por meio de modelos. Na modelagem, busca-se descrever uma realidade com maior nível de precisão (DIAS et al., 2005). Os modelos de crescimento e produção florestal permitem simular a dinâmica natural de um povoamento e prever a sua produção ao longo do tempo, em diferentes possibilidades de exploração (VANCLAY, 1994). 
Conhecer o estoque atual e estimar a produção futura é essencial no planejamento de um empreendimento florestal. O inventario florestal é, assim, fundamental para o manejo, pois ele irá fornecer os dados necessários para se planejar e realizar as atividades subsequentes como colheita, análise financeira, como também os custos e a receita. Os modelos de crescimento e produção de povoamentos são empregados nestes processos de decisão. A coleta dos dados deverá ser baseada no tipo de modelagem empregado, assim como atender aos objetivos do manejo (TAQUETTI, 2014).

Para isso, existem diversos tipos de modelos empíricos consagrados na literatura de acordo com o nível de detalhamento (CLUTTER et al., 1983; CAMPOS e LEITE, 2013; CASTRO et al., 2013): a) modelos explícitos ou de povoamento total, que fornecem estimativa da produção para o povoamento por unidade de área a partir de informações relacionadas ao povoamento em geral, como: idade, índice de locale uma medida de densidade; b) modelos implícitos ou por classe diamétrica, que avaliam a produção, considerando a estrutura dos povoamentos florestais e utilizam certas estatísticas como idade, sítio e uma variável de densidade para estimar os parâmetros da função de frequência dos diâmetros; e c) modelos para árvore individual que avaliam a produção florestal considerando a árvore individualmente.

A modelagem do crescimento e da produção de povoamentos de eucaliptono Brasil tem sido feita principalmente por meio de modelos em nível de povoamento, por limitação de base de dados ou devido a decisão pessoal do usuário, visto que os tipos de informação fornecida por esses modelos atendem plenamente as necessidades dos manejadores (CASTRO et al., 2013). É comum que os modelos em nível de povoamento apresentem apenas a idade como variável independente. Por um lado, isso facilita o processamento e análise uma vez que somente uma variável explicativa é usada. Entretanto, o uso desses modelos deve ser restrito a áreas homogêneas, caso contrário, podem ocorrer sérios prejuízos a sua exatidão (TAQUETTI, 2014).

De acordo com Gorgens et al. (2007), muitos modelos têm sido utilizados para estimar o crescimento e a produção, dentre os quais podem-se citar os modelos de Schumacher (1939), Buckman (1962) e o de Clutter (1963). 
Sendo uma abstração da realidade, todo modelo estará errando de alguma forma. A escolha do modelo de crescimento e produção depende da informação pretendida, do nível de detalhamento necessário, das características do povoamento e do tipo de dados disponíveis (VANCLAY, 1994).

Os modelos em nível de povoamento podem ser subdivididos em: modelos de produção, os quais utilizam a idade e o índice de local como variáveis independentes, e estimam a produção corrente e futura, gerando tabelas de produção; e modelos de crescimento e produção, que, além da idade e do índice de local, utilizam uma variável de densidade do povoamento como variável independente. Nesse caso é estimado o crescimento e a produção, corrente e futura, sendo geradas tabelas de produção de densidade variável (CAMPOS e LEITE, 2013).

No país, o modelo de Clutter é o mais difundido, devido à sua menor complexidade e pelo fato de atender às exigências de planejamento para produção de madeira de uso único (DIAS et al., 2005; GÖRGENS et al., 2007; CAMPOS e LEITE, 2013).

Para o ajuste do modelo de Clutter (1963), é necessário obter as informações de volume, área basal, índice de local e idade do povoamento em cada parcela. Os valores de índices de localsão obtidos a partir dos melhores métodos de classificação, que devem ser testados.

$$
\left\{\begin{array}{l}
\operatorname{LnV} V_{2}=\beta_{0}+\beta_{1}\left(\frac{1}{I_{2}}\right)+\beta_{2} S_{1}+\beta_{3} \operatorname{Ln} B_{2}+\operatorname{Ln} \varepsilon \\
\operatorname{Ln} B_{2}=\operatorname{Ln} B_{1}\left(\frac{I_{1}}{I_{2}}\right)+\alpha_{0}\left(1-\frac{I_{1}}{I_{2}}\right)+\alpha_{1}\left(1-\frac{I_{1}}{I_{2}}\right) S_{1}+\operatorname{Ln} \varepsilon
\end{array}\right.
$$

Em que: $S_{l}$ é o índice de local calculado por cada um dos métodos utilizados para a classificação do local; $I_{1}$ é a idade atual (meses); $I_{2}$ a idade futura (meses); $B_{1}$ é a área basal inicial $\left(\mathrm{m}^{2} . h a^{-1}\right) ; B_{2}$ é a área basal futura $\left(\mathrm{m}^{2} . h \mathrm{a}^{-1}\right) ; V_{2}$ é o volume futuro com casca $\left(\mathrm{m}^{3} . h a^{-}\right.$ $\left.{ }^{1}\right) ; \beta_{0}, \beta_{1}, \beta_{2}, \beta_{3}$ são os parâmetros do modelo que projetam o volume; $\alpha_{0}$ e $\alpha_{1}$ são os parâmetros do modelo que projetam a área basal; e $\varepsilon$ é o erro aleatório.

Segundo Campos e Leite (2013) este é um modelo do tipo povoamento total, de densidade variável, compatível, explícito e consistente. É do tipo povoamento total, porque a variável estimada é o volume por unidade de área, independentemente da classe de tamanho da árvore. É do tipo densidade variável porque permite estimar a produção para diferentes 
níveis de área basal inicial $\left(B_{1}\right.$ ou $\left.B_{i}\right)$. Tem características compatível, pois a equação de crescimento quando integrada fornece a equação de produção, e a derivada desta resulta na equação de crescimento. Trata-se de um modelo explícito, porque a produção em volume é calculada diretamente. É consistente, pois as estimativas podem ser obtidas projetando-se a área basal ano a ano, ou diretamente de um para qualquer outro ano, com intervalos irregulares e, ainda, porque, ao estimar a produção em área basal para uma mesma idade, resulta em valores idênticos àqueles observados.

O modelo de CLUTTER é largamente utilizado na área florestal para prognose da produção, e suas qualidades são amplamente estudadas e discutidas na literatura florestal (GÖRGENS et al., 2007).

Conforme Campos e Leite (2013), duas características do modelo de Clutter devem ser imediatamente verificadas: o parâmetro $\beta_{1}$ deverá ser negativo e o coeficiente $\alpha_{1}$, positivo. 


\section{MATERIAL E MÉTODOS}

\subsection{LOCALIZAÇÃO DA ÁREA DE ESTUDO}

Os dados foram disponibilizados por uma empresa florestal com povoamentos de Eucalyptusspp. no Estado de Minas Gerais -MG. As florestas estudadas possuíam,juntas, área de 83.402hectares eestavam localizadas ao longo de dezessete municípios na região Norte, Centro e Sul do Estado.Uma grande variedade de solos compreendeessas áreas, tais como os neossolos, cambissolos, plintossolos e latossolos.

Segundo a classificação de Köppen os climas das regiões são do tipo Cwa e Aw. Estes caracterizam-se por apresentaremuma estação seca nos meses de maio a julho, e os meses de maiorprecipitação são janeiro e fevereiro. As médias anuais estão próximas a $1.330 \mathrm{~mm}$ deprecipitação e $21^{\circ} \mathrm{C}$ de temperatura média anual (KÖPPEN, 1931).

\subsection{CARACTERIZAÇÃO DOS DADOS}

Foram utilizados dados provenientes de 1.643 parcelas permanentes provenientes de inventário florestal contínuo (IFC), em povoamentos de híbridos de Eucalyptus spp., com idades variando de 17 a 114 meses medidos entre os anos de 2006 a 2013.

As parcelas foram divididas aleatoriamente em duas partes, uma contendo $70 \%$ delas, totalizando 1.150 parcelas, a qual chamou-se de dados para "ajuste", e outra parte, contendo os 30\% restante, correspondente a 493 parcelas, a qual chamou-se de dados para "validação".

As parcelas permanentes foram medidas anualmente (pelo menos em três ocasiões diferentes) e possuíam formato retangular, em média, com dimensão de $300 \mathrm{~m}^{2}$. Em cada ocasiãoforam mensurados o diâmetro dos indivíduos a 1,30 m de altura (DAP, em cm), considerando o nível de inclusão de $4 \mathrm{~cm}$, com o auxílio de uma suta; e a altura total $(H t$, em $\mathrm{m}$ ) das 10 primeiras árvores de cada parcela utilizando o clinômetro digital.

Além disso, mensurou-se a altura das árvores dominantes de cada parcelaseguindo o conceito de Assmann (1970 apud BILA, 2010), que diz respeito à altura média das 100 
árvores mais grossas por hectare, que em outras palavras se refere à altura de uma árvore dominante a cada $100 \mathrm{~m}^{2}$. As árvores foram identificadas como dominantes na primeira ocasião da medição das parcelas. Os critérios utilizados para a qualificação dessa dominância foram características de sanidade, ausência de bifurcação, tortuosidade e danos e copa situada no dossel superior recebendo radiação solar direta.

O povoamento possuía espaçamentos variados entre talhões, com os seguintes arranjos espaciais: $3,0 \mathrm{~m} \times 3,3 \mathrm{~m} ; 3,0 \mathrm{~m} \times 2,5 \mathrm{~m} ; 3,0 \mathrm{~m}$ x 3,0 m; 3,0 m x 2,8 m e 3,3 m x 2,0 m.

Os dados em nível de árvore foram processados pela própria empresa, sendo geradas estimativas por parcela e ano de medição das seguintes variáveis:Idade (meses), média da Altura Dominante ( $H d$ em metros), Área Basal $\left(m^{2} \cdot h a^{-1}\right)$ e Volume Total com casca $\left(V_{c c} m^{3} \cdot h a^{-1}\right)$ conforme Tabela 1 .

Tabela 1: Amplitude e valores de idade, média da Altura Dominante $(H d)$, Área Basal e Volume com casca de toda a população estudada.

\begin{tabular}{cc|ccc|ccc|ccc}
\hline \multicolumn{3}{c}{ Idade (meses) } & \multicolumn{3}{c}{$\boldsymbol{H d}(\mathbf{m})$} & \multicolumn{4}{c}{ Área Basal $\left(\boldsymbol{m}^{2} \cdot \boldsymbol{h \boldsymbol { a } ^ { - 1 } )}\right.$} & \multicolumn{3}{c}{ Vcc $\left(\boldsymbol{m}^{3} \cdot \boldsymbol{h \boldsymbol { a } ^ { - 1 }}\right)$} \\
\hline Mín. & Máx. & Mín. & Méd. & Máx. & Mín. & Méd. & Máx. & Mín. & Méd. & Máx. \\
17 & 114 & 6,00 & 23,68 & 41,30 & 2,31 & 23,68 & 39,21 & 4,58 & 200,00 & 625,09 \\
\hline
\end{tabular}

\subsection{MODELAGEM DE CURVAS DE ÍNDICE DE LOCAL}

Para a construção das curvas de índices de local, o primeiro passo foi estabelecer a idade técnica de corte (ITC) média do povoamento, que foi usada para a definição da idade índice (MOSER e HALL, 1969; BURGER,1976; CAMPOS e LEITE, 2013).

Para tanto, foi calculado o Incremento Médio Mensal (IMM) e o Incremento Corrente Mensal (ICM) a partir das estimativas de volumeobtidas pelo modelo logístico, onde foram ajustados osdados de Volume $\left(m^{3} \cdot h a^{-1}\right)$ em função da Idade (meses) com os dados de ajuste, conforme reportado por Campos e Leite (2013): 


$$
\begin{gathered}
I M M=V_{i} / I_{i} \\
I C M=\left(V_{i}-V_{i-1}\right) /\left(I_{i}-I_{i-1}\right)
\end{gathered}
$$

$V_{i}=$ volume $\left(m^{3} \cdot h a^{-1}\right)$ em determinada idade; $I_{i}=$ idade em que $i$ corresponde ao mês; $i-1=$ valores da idade no mês imediatamente anterior.

A idade técnica de corte foi determinada ao igualar as expressões de IMM e ICM, ou mesmo no ponto onde o IMM foi máximo.

A classificação da capacidade produtiva de cada parcela foi feita empregando quatro diferentes métodos: a) método da Curva-Guia (CLUTTER et al., 1983); b) método das Equações das Diferenças (CAMPOS e LEITE, 2013);c) Hammer (CAMPOS e LEITE, 2013) e d) Predição de Parâmetros (CAMPOS e LEITE, 2013), todos eles assumindo como idade-índice a idade técnica de corte média do povoamento.

Todos os modelos a seguir foram ajustados às parcelas separadas para ajuste, sendo assim, foram utilizados 4820 pares de valores de altura dominante e idade. A estimativa do crescimento médio em altura dominante ao longo do tempo foi obtida partindo-se da premissa de que quando a idade do povoamento for igual à idade de índice, a altura dominante $(H d)$ será igual ao índice de local, conforme apresentado por Campos e Leite (2013).

Para o método da Curva Guia utilizou-se o modelo de Schumacher em sua forma linearizada:

$$
\operatorname{LnHd}=\beta_{0}+\beta_{1}\left(\frac{1}{I}\right)+\varepsilon
$$

Onde: $L n H d=$ Logaritmo neperiano da altura dominante; $I=$ idade em meses; $\beta_{0}$ e $\beta_{1}$ são os parâmetros do modelo; $\varepsilon$ é o erro aleatório.

A partir da equação 4, uma equação de índice de local foi obtida ao observar a condição de que, quando a idade $(I)$ do povoamento for igual à idade de índice $\left(I_{i}\right)$, a altura dominante é igual ao índice de local $\left(H d=S\right.$ e $\left.I=I_{i}\right)$. Deste modo tem-se que: 


$$
\operatorname{Ln}(S)=\beta_{0}+\beta_{1}\left(\frac{1}{I_{i}}\right)+\varepsilon
$$

Onde: $L n S=$ Logaritmo neperiano do índice de local; $I_{i}=$ idade índice; $\beta_{0} e \beta_{1}$ são os parâmetros do modelo; $\varepsilon$ é o erro aleatório.

Seguindo as considerações anteriores, isolando $\beta_{0}$ na equação 4 e substituindo-o na equação 5, pode-se escrever:

$$
\operatorname{Ln}(H d)=\operatorname{Ln}(S)+\beta_{1}\left[\left(\frac{1}{I}\right)-\left(\frac{1}{I_{i}}\right)\right]+\varepsilon
$$

Onde: $L n H d=$ Logaritmo neperiano da altura dominante; $\operatorname{LnS}=$ logaritmo neperiano do índice de local; $I=$ idade em meses; $I_{i}=$ idade índice; $\beta_{l}$ é parâmetro do modelo; $\varepsilon$ é o erro aleatório.

Esta expressão foi utilizada para construir as curvas de índice de local pelo método da curva guia. Atribuindo-se valores para $S$ compatíveis com a variação da altura dominante na idade índice e variando a idade ( $I$ ), foram geradas curvas de índice de local.

Para o método da Equação das Diferenças, também utilizou-se o modelo de Schumacher (1939) em sua forma linearizada, sem a constante $\beta_{0}$ :

$$
\operatorname{LnHd}=\beta_{1}\left(\frac{1}{I}\right)+\varepsilon
$$

Onde: $L n H d=$ Logaritmo neperiano da altura dominante; $I=$ idade em meses; $\beta_{l}$ é o parâmetro do modelo; $\varepsilon$ é o erro aleatório.

Inicialmente, utilizando pares consecutivos de idade e altura dominante (formato $I_{1}-I_{2}$ ), determinou-se as diferenças sucessivas, $L n H d_{2}-L n H d_{1} \mathrm{eI}_{2}^{-1}-I_{1}^{-1}$, em que 1 refere-se à medição atual e 2 à medição imediatamente posterior. Em seguida ajustou-se o modelo $Y=\beta_{1} X+\varepsilon$, em que $Y=L n H d_{2}-L n H d_{1}$ e $X=I_{2}^{-1}-I_{1}^{-1}$. Ao isolar o termo $L n H d_{2}$, resultou na expressão $\operatorname{LnH} d_{2}=\operatorname{LnH} d_{1}-\hat{\beta}_{1}\left(I_{2}^{-1}-I_{1}^{-1}\right)$. Fazendo $I_{1}$ igual à idade índice e $H d_{l}$ igual ao índice de local, foi obtida a equação 8 , utilizada para determinar as curvas de índice de local: 


$$
\operatorname{LnHd}=\operatorname{LnS}+\hat{\beta}_{1}\left[\left(\frac{1}{I}\right)-\left(\frac{1}{I_{i}}\right)\right]+\varepsilon
$$

Onde: $L n H d=$ Logaritmo neperiano da altura dominante; $L n S=$ logaritmo neperiano do índice de local; $I=$ idade em meses; $I_{i}=$ idade índice; $\hat{\beta}_{1}$ é parâmetro do modelo; $\varepsilon$ é o erro aleatório.

A mesma equação linearizada, utilizada para o método da curva guia foi também utilizada no método de Hammer:

$$
\operatorname{LnHd}=\beta_{0}+\beta_{1}\left(\frac{1}{I}\right)+\varepsilon
$$

Onde: $L n H d=$ Logaritmo neperiano da altura dominante; $I=$ idade em meses; $\beta_{0}$ e $\beta_{1}$ são os parâmetros do modelo; $\varepsilon$ é o erro aleatório.

Em seguida, estimou-se valores de $\beta_{0}$ na variação de $S$ identificados na amplitude de $H d$ na $I_{i}$. Neste método, conforme Hammer (1981), o parâmetro $\beta_{0}$ do modelo original (9) foi substituído por outra equação linear simples $\left(\beta_{0}=\alpha_{0}+\alpha_{1} S+\varepsilon\right)$, de forma que as curvas de índices de local passassem por alturas prefixadas coincidentes com índices de local definidos, obtendo-se a expressão abaixo, a qual foi utilizada para construir as curvas de índice de local nesse método:

$$
\operatorname{LnHd}=\left(\hat{\alpha}_{0}+\hat{\alpha}_{1} S\right)+\hat{\beta}_{1}\left(\frac{1}{I}\right)+\varepsilon
$$

Onde: $\operatorname{LnHd}=$ Logaritmo neperiano da altura dominante, $S=$ índice de local; $I=$ idade em meses; $\hat{\alpha}_{0} \hat{\alpha}_{1}$ e $\hat{\beta}_{1}$ são parâmetros do modelo; $\varepsilon$ é o erro aleatório.

Para o método da Predição de Parâmetros foi utilizado o seguinte modelo linear:

$$
H d=\beta_{0}+\beta_{1} * \operatorname{Ln}(I)+\varepsilon
$$

Onde: $H d=$ altura dominante; $L n(I)=$ logaritmo neperiano da idade em meses; $\beta_{0}, \beta_{1}$, são os parâmetros do modelo; $\varepsilon$ é o erro aleatório.

Este modelo foi utilizado para relacionar altura dominante e idade para cada parcela separadamente, resultando em 1.150 ajustes, o que torna a aplicabilidade do método mais complexa que os demais. 
Em seguida, foi substituída a idade índice em cada uma das regressões, encontrando-se o valor de índice de local para cada parcela. Cada parâmetro estimado da equação (11)foi relacionado com os índices de local por regressões lineares, sendo: $\beta_{0}=\alpha_{0}+\left(\alpha_{1} S\right) \mathrm{e}$ $\beta_{1}=\alpha_{0}+\left(\alpha_{1} S\right)$. Então, essas equações foram substituídas na equação inicial (11), obtendo-se a expressão abaixo utilizada para construção das curvas de índice de local:

$$
\operatorname{LnHd}=\left(\alpha_{0}+\left(\alpha_{1} S\right)\right)+\left(\alpha_{0}+\left(\alpha_{1} S\right)\right) * \operatorname{Ln}(I)
$$

Onde: $\operatorname{LnHd}=$ Logaritmo neperiano da altura dominante; $S=$ índice de local; $\operatorname{Ln}(I)=$ logaritmo neperiano da idade em meses; $\alpha_{0} \mathrm{e} \alpha_{l}$ são os parâmetros do modelo.

As curvas de capacidade produtiva, geradas por cada um dos métodos, foram separadas em três categorias: I - alta capacidade produtiva, II - média capacidade produtiva e III - baixa capacidade produtiva.

\subsection{MODELAGEM DO CRESCIMENTO E DA PRODUÇÃO EM NÍVEL DE POVOAMENTO}

Após a estimação do índice de local das parcelas, pelos quatro métodos estudados, foi feito o ajuste do modelo de Clutter (13), sendo um ajuste utilizando a variável independente site (S)calculadapor cada método de classificação da capacidade produtiva, utilizando os dados separados para ajuste. Utilizou-se para tanto, informações de volume, área basal, índice de local e idade do povoamento em cada parcela. Ajustou-se ainda, um modelo de Clutter sem utilizar a variável "S". Os modelos foram ajustados pelo método dos mínimos quadrados em dois estágios, utilizando o software Eviews5.0.

$$
\left\{\begin{array}{l}
\operatorname{Ln} B_{2}=\operatorname{Ln} B_{1}\left(\frac{I_{1}}{I_{2}}\right)+\alpha_{0}\left(1-\frac{I_{1}}{I_{2}}\right)+\alpha_{1}\left(1-\frac{I_{1}}{I_{2}}\right) S_{i}+\operatorname{Ln} \varepsilon \\
\operatorname{LnV} V_{2}=\beta_{0}+\beta_{1} / I_{2}+\beta_{2} S_{i}+\beta_{3} \operatorname{Ln} B_{2}+\operatorname{Ln} \varepsilon
\end{array}\right.
$$

Em que: (13) modelo de Clutter; $S_{i}$ é o índice de local calculado por cada um dos métodos utilizados para a classificação do local; $I_{1}$ é a idade atual em meses; $I_{2}$ a idade futura em meses; $B_{1}$ é a área basal inicial $\mathrm{em} m^{2} \cdot h a^{-1} ; B_{2}$ é a área basal futura em $m^{2} . h a^{-1} ; V_{2}$ é o volume futuro com casca em $m^{3} \cdot h a^{-1} ; \beta_{0}, \beta_{1}, \beta_{2}, \beta_{3}$ são os parâmetros do modelo que projeta o 
volume; $\alpha_{0}$ e $\alpha_{1}$ são os parâmetros do modelo que projeta a área basal; e $\varepsilon$ é o erro aleatório.

É importante ressaltar que, ao utilizar o método dos mínimos quadrados em dois estágios, os testes estatísticos convencionais $\mathrm{F}$ e t não são estritamente aplicáveis, e que o coeficiente de determinação $\left(\mathrm{R}_{\hat{y} \mathrm{y}}^{2}\right)$ deve ser visto com cautela (DEBERTIN, 1975).

\subsubsection{Estatísticas de avaliação do sistema de Clutter}

Para avaliar a precisão das equações que estimam a área basal e o volume, utilizando a variável "S",foram calculadas as seguintes estatísticas:significância dos parâmetros das equações $(\alpha=0,05)$; BIAS (14); raiz quadrada do erro médio (RQEM) (15); R (coeficiente de correlação entre as variáveis Y estimadas e observadas) (16); $\bar{R}^{2}$ ajus.(coeficiente de determinação ajustado) (17) e a distribuição gráfica dos resíduos (SIIPILEHTO, 2000):

$$
\begin{gathered}
B I A S=\frac{\sum_{i=1}^{n}\left(Y_{i}-\widehat{Y}_{i}\right)}{n} \\
R Q E M=\sqrt{\frac{\sum_{i=1}^{n}\left(Y_{i}-\widehat{Y}_{i}\right)^{2}}{n-1}} \\
r_{\hat{y}, y}=\frac{C \hat{o} v(\hat{y}, y)}{\sqrt{v(\hat{y}) v(y)}} \\
R^{2} \text { ajus. }=1-\frac{n-1}{n-(k+1)}\left(1-R^{2}\right)
\end{gathered}
$$

$Y_{i}=$ Produção volumétrica $\left(\mathrm{m}^{3} \cdot h \mathrm{a}^{-1}\right)$ observada por parcela; $\hat{Y}_{i}=$ Projeção da produção volumétrica $\left(m^{3} \cdot h a^{-1}\right)$ por parcela; $\mathrm{n}=$ Número de parcelas; $\bar{Y}=$ Produção volumétrica média $\left(m^{3} \cdot h a^{-1}\right)$ observada por parcela; $S=$ Desvio padrão; $\bar{R}^{2}=$ Coeficiente de determinação ajustado; $R^{2}=$ Coeficiente de determinação; $(k+1)=$ Número de variáveis explicativas mais a constante.

Também foi calculado o erro padrão $\left(S_{y x}\right)$ e o coeficiente de variação $\left(S_{y x} \%\right)$ conforme fórmulas a seguir: 


$$
\begin{gathered}
S_{y x}=\sqrt{\sum_{i=1}^{n}\left(\frac{\left(Y_{i}-\hat{Y}_{i}\right)^{2}}{n}\right)} \\
S_{y x} \%=\frac{S_{y x}}{\bar{Y}_{i}} x 100
\end{gathered}
$$

$Y_{i}=$ Produção volumétrica $\left(m^{3} \cdot h a^{-1}\right)$ observada por parcela; $\hat{Y}_{i}=$ projeção da produção volumétrica $\left(\mathrm{m}^{3} \cdot h \mathrm{~h}^{-1}\right)$ por parcela; $\mathrm{n}=$ número de parcelas; $\bar{Y}_{i}=$ produção volumétrica média $\left(m^{3} \cdot h a^{-1}\right)$ observada por parcela.

\subsubsection{Validação dos modelos de Clutter}

As validações dos sistemas de equações obtidosforam feitas aplicando-os aos $30 \%$ das parcelas que não foram utilizadas no ajuste dos modelos. Para tanto, a partir dos dados de medições realizadas em uma primeira ocasião, fez-se as projeções para as idades seguintes e assim sucessivamente até a última idade de cada parcela.

A seleçãodo melhor modelo foi realizada atravésdas estatísticas demonstradas nas equações 14 a 19 e pela análise gráfica dos resíduos.Segundo Cabacinha (2003), existem dois tipos de validação de modelos: validação estatística e validação preditiva. Ambas as validações têm como objetivo selecionaro melhor modelo a ser utilizado na estimativa volumétrica. A validaçãoestatística ocorre no contexto dos dados utilizados para o ajuste. Esta validação verifica as pressuposições dos gráficos de resíduos e a qualidade do ajuste (coeficiente de determinação e valor de F). Por outro lado, a validação preditiva ocorre no contextode novos dados, do mesmo povoamento, que gerou os dados do ajuste. Neste trabalho utilizou-se a validação preditiva. 


\section{RESULTADOS E DISCUSSÃO}

\subsection{MODELAGEM DE CURVAS DE ÍNDICE DE LOCAL}

A idade técnica de corte ocorre onde o incremento médio é máximo, e igual ao incremento corrente, ou seja, exatamente no ponto onde as curvas de IMM e IMC se cruzam. Este ponto define a máxima taxa média de incremento da produção que determinada espécie pode alcançar num local particular (CAMPOS e LEITE, 2013). Desse modo, a idade técnica de corte como a idade índice do povoamento foi de 71 meses, sendo esta, utilizada como referência para o cálculo dos Índices de Local (Figura 1).

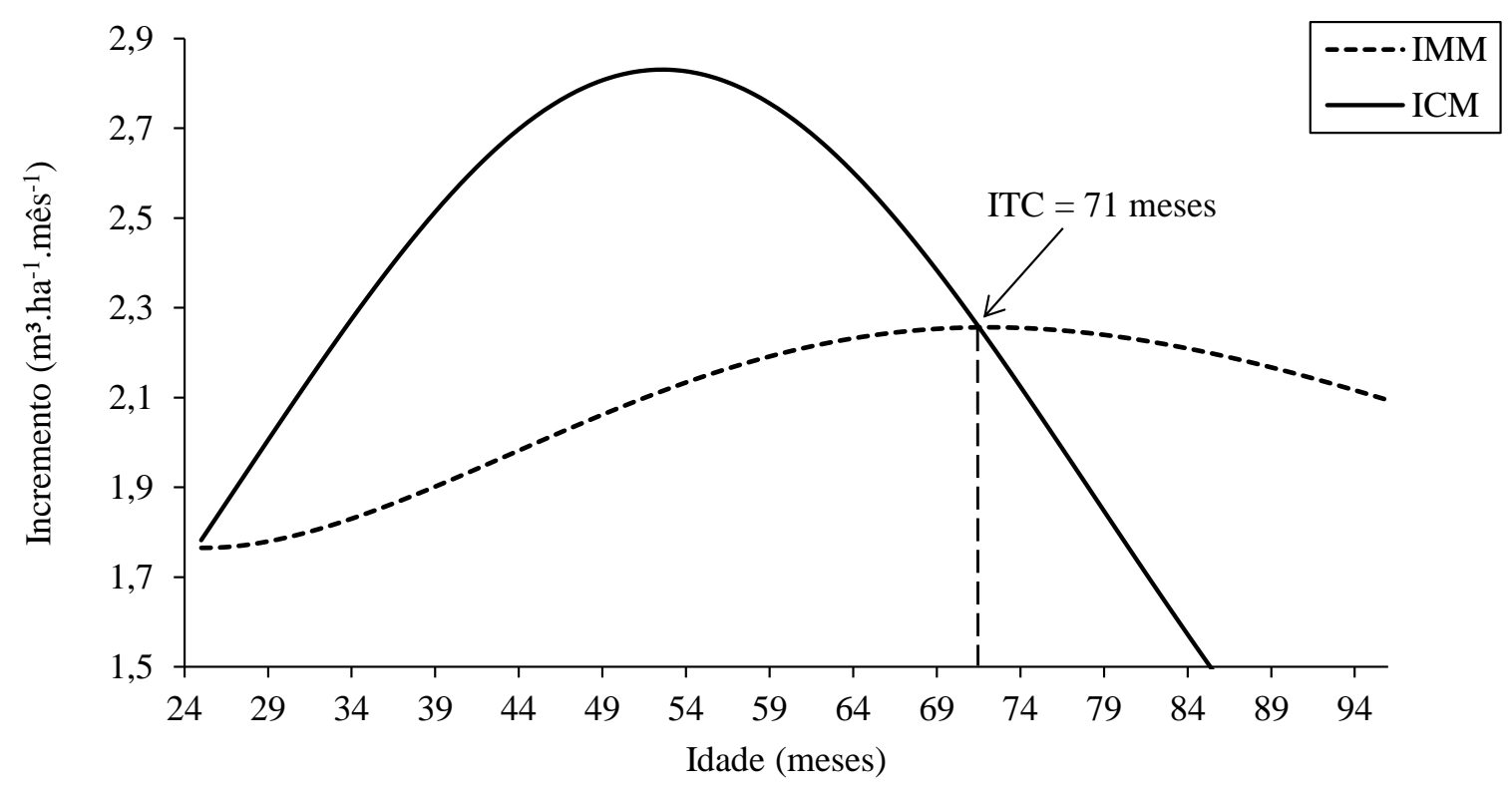

Figura 1 - Gráfico de estabelecimento da ITC (Idade Técnica de Corte). O ponto de cruzamento do IMM (Incremento Médio Mensal) e do ICM (Incremento Corrente Mensal) acontecendo aos 71 meses.

Obtido a idade índice e partindo do conceito de que $(S)$ é igual à altura dominante quando a idade do povoamento for igual à idade-índice, foram obtidas as equações para construção das curvas de local e os parâmetros estatísticos destas, utilizando os dados separados para ajuste, conforme descrito por Campos e Leite (2013).

Para o método da Curva Guia utilizou-se a equação: 


$$
\operatorname{Ln}(H d)=\operatorname{Ln}(S)-27,9241 x\left[\left(\frac{1}{I}\right)-\left(\frac{1}{71}\right)\right]
$$

As estatísticas da análise de regressão para o ajuste foram: $\mathrm{R}^{2}$ ajustado $=84,58 \%$ e erro padrão de $11,34 \%$.

Para o método da Equação das Diferenças utilizou-se a equação:

$$
\operatorname{Ln}(H d)=\operatorname{Ln}(S)-28,2447 \times\left[\left(\frac{1}{I}\right)-\left(\frac{1}{71}\right)\right]
$$

As estatísticas da análise de regressão foram: $\mathrm{R}^{2}$ ajustado $=87,41 \%$ e erro padrão de $7,95 \%$.

Para o método de Hammer utilizou-se a equação:

$$
\operatorname{LnHd}=(2,7092+0,0360 S)+27,9241\left(\frac{1}{I}\right)
$$

As estatísticas da análise de regressão foram: $\mathrm{R}^{2}$ ajustado $=84,58 \%$ e erro padrão de $11,34 \%$. Para a equação secundária $\left(\beta_{0}=\hat{\alpha}_{0}+\hat{\alpha}_{1} * S\right)$ foram: $\mathrm{R}^{2}$ ajustado $=99,65 \%$ e erro padrão de $0,79 \%$.

Para o método da Predição de Parâmetros utilizou-se a equação:

$$
(H d)=((2,3364+(-0,0591) * S)+(0,0145+0,0216 * S) * \operatorname{Ln}(I))
$$

As estatísticas da análise de regressão para a equação principal variaram entre $57 \%$ e 98\% para $\mathrm{R}^{2}$ ajustado e erro padrão de $0,01 \%$ a $0,07 \%$ (entre os 1150 ajustes). As estatísticas da análise de regressão para as equações secundárias que estimaram o $\beta_{0}$ foram: $\mathrm{R}^{2}$ ajustado $=10,45 \%$ e erro padrão de $61,73 \%$. Para o parâmetro $\beta_{1}$ foram: $\mathrm{R}^{2}$ ajustado $=$ $22,29 \%$ e erro padrão de $14,45 \%$.

Foram geradas seis curvas de índice de local, com amplitude de classe de 2 metros para todos os métodos, sendo estas: $\mathrm{S}=23(H d \leq 24,0 \mathrm{~m}), \mathrm{S}=25(24,0 \mathrm{~m}<H d \leq 26,0 \mathrm{~m}), \mathrm{S}=$ 
$27(26,0 \mathrm{~m}<H d \leq 28,0 \mathrm{~m}), \mathrm{S}=29(28,0 \mathrm{~m}<H d \leq 30,0 \mathrm{~m}), \mathrm{S}=31(30,0 \mathrm{~m}<H d \leq 32,0 \mathrm{~m}) \mathrm{e}$ $\mathrm{S}=33(32,0 \mathrm{~m} \leq H d)$. As curvas $\mathrm{S}=23$ e $\mathrm{S}=25$ foram consideradas como de baixa produtividade; as curvas $\mathrm{S}=27$ e $\mathrm{S}=29$ foram consideradas como de média produtividade e as curvas $S=31$ e $S=33$ foram consideradas como de alta produtividade.

As curvas geradas pelos quatro métodos apresentam padrão exponencial e anamórfico, representando bem a amplitude de $H d$ dos dados, conforme observado na Figura 2.
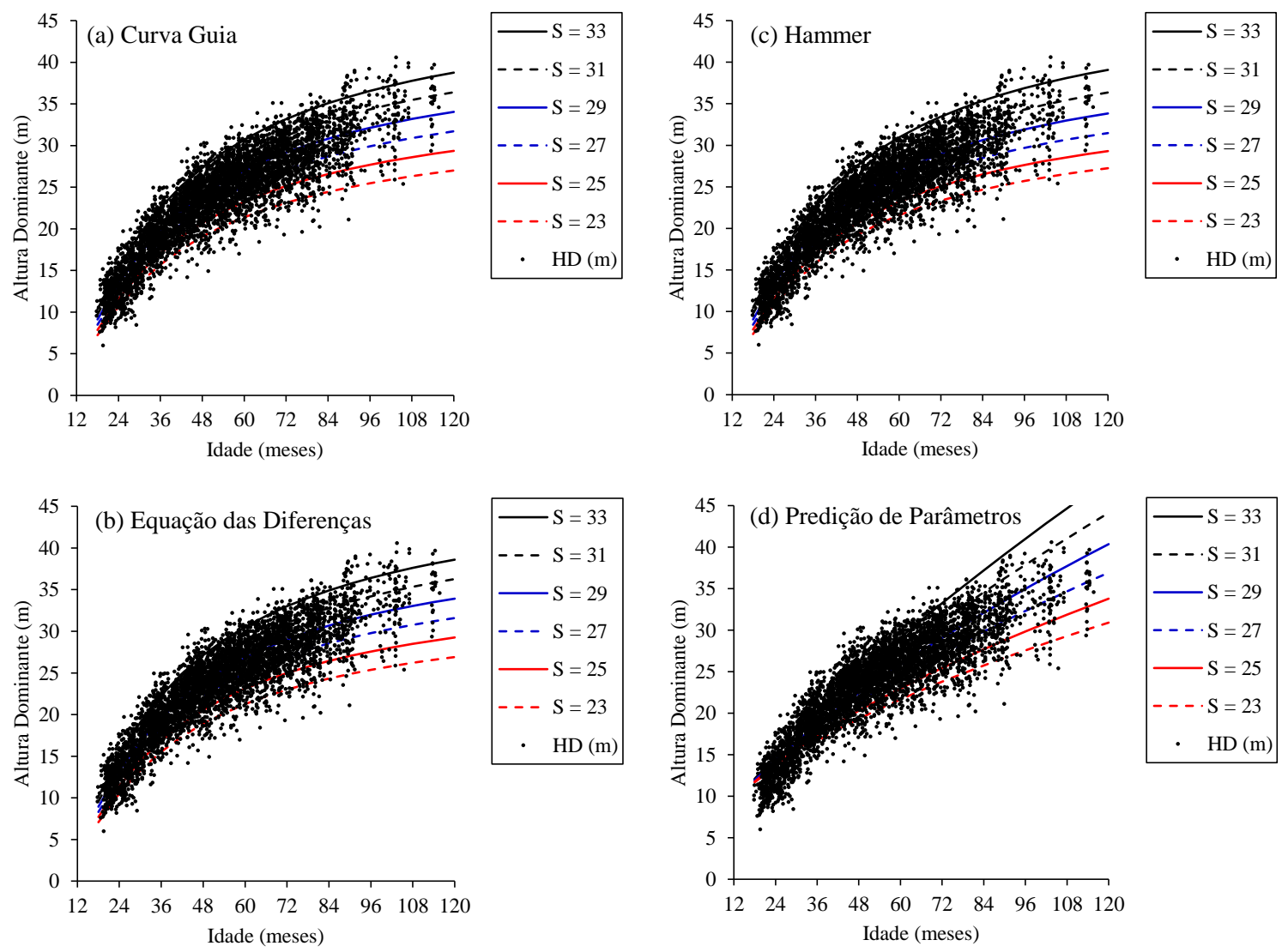

Figura 2 - Classificação da capacidade produtiva pelos quatro métodos avaliados utilizando-se os dados separados para ajuste do modelo de Clutter.

A Tabela 2 traz a comparação entre os métodos de classificação da capacidade produtivaavaliados, mostrando o percentual de igualdade entre os métodos na classificação das parcelasde ajuste tomadas na última medição de cada parcela. Vale ressaltar a semelhança na classificação entre os métodos da Curva Guia quando comparado com os métodos da Equação das Diferenças e Hammer, assim como a semelhança entres estes dois. 
Tabela 2 - Percentual de igualdade de classificação da capacidade produtiva entre os métodos avaliados utilizando os dados separados para ajuste.

\begin{tabular}{lcccc}
\hline \multicolumn{1}{c}{$\begin{array}{c}\text { Método de } \\
\text { Classificação }\end{array}$} & Curva Guia & $\begin{array}{c}\text { Equação das } \\
\text { Diferenças }\end{array}$ & Hammer & $\begin{array}{c}\text { Predição de } \\
\text { Parâmetros }\end{array}$ \\
\hline Curva Guia & 1 & $99,40 \%$ & $97,30 \%$ & $51,70 \%$ \\
Equação das Diferenças & - & 1 & $97,80 \%$ & $51,30 \%$ \\
Hammer & - & - & 1 & $52,40 \%$ \\
Predição de Parâmetros & - & - & - & 1 \\
\hline
\end{tabular}

A semelhança de classificação entre os métodos da Curva Guia, Equação das Diferenças e Hammer se dá pela pequena variação de metodologia entre eles. O método da Predição de Parâmetros segue uma metodologia muito diferente dos outros três, necessitando a aplicação de análise de regressão para cada parcela separadamente. Consequências dessa diferença de classificação serão observadas durante a validação dos modelos de Clutter ajustados.

MIGUEL et al. (2011) estudando a classificação de sítio para plantios de Eucalyptus urophylla em Niquelândia, estado de goiás, concluiu que os resultados obtidos pelo método da curva guia para classificação de local mostraram-se adequadospara a base de dados estudada.

Castro et al. (2015) estudando povoamentos não desbastados observou que a classificação da capacidade produtiva por meio de índices de local foi eficiente pelos dois métodos avaliados, curva guia e equação das diferenças, e os modelos de Clutter ajustados utilizando as variáveis $S$ pelos dois métodos foram precisos.

Cunha Neto et al. (1996) utilizou o método da Equação das Diferenças para construção de curvas de índice de local para Eucalyptus grandis e Eucalyptus urophylla, chegando a conclusão de que o método foi eficiente para a construção das curvas de índice de local para essas espécies.

Castro et al. (2016) estudando a modelagem do crescimento e da produção de povoamentos de Eucalyptus spp. em nível de distribuição diamétrica utilizando índice de local concluiu que a classificação da capacidade produtiva por meio de índices de local foi eficiente pelos 
dois métodos avaliados (curva guia e equação das diferenças), sendo selecionado o método da curva-guia devido à sua simplicidade e facilidade de aplicação.

\subsection{MODELAGEM DO CRESCIMENTO E DA PRODUÇÃO EM NÍVEL DE POVOAMENTO}

O modelo de Clutter ajustado para o método da curva guia é apresentado no sistema de equações24 e para o método da equação das diferenças, Hammer e predição de parâmetros, nos sistemas 25, 26 e 27 respectivamente.O modelo com a exclusão dos parâmetros relacionados à variável "S" é apresentado no sistema de equações 28 .

$$
\begin{aligned}
& \left\{\begin{array}{l}
\operatorname{Ln} B_{2}=\operatorname{Ln} B_{1}\left(\frac{I_{1}}{I_{2}}\right)+3,9416\left(1-\frac{I_{1}}{I_{2}}\right)-0,0070\left(1-\frac{I_{1}}{I_{2}}\right) S_{i} \\
\operatorname{LnV} V_{2}=1,4691+\frac{-19,3373}{I_{2}}+0,0179\left(S_{i}\right)+1,2403 \operatorname{Ln}\left(B_{2}\right)
\end{array}\right. \\
& \left\{\begin{array}{l}
L n B_{2}=\operatorname{Ln} B_{1}\left(\frac{I_{1}}{I_{2}}\right)+3,9302\left(1-\frac{I_{1}}{I_{2}}\right)-0,0066\left(1-\frac{I_{1}}{I_{2}}\right) S_{i} \\
\operatorname{Ln} V_{2}=1,4727+\frac{-19,5574}{I_{2}}+0,0177\left(S_{i}\right)+1,2418 \operatorname{Ln}\left(B_{2}\right)
\end{array}\right. \\
& \left\{\begin{array}{l}
\operatorname{Ln} B_{2}=\operatorname{Ln} B_{1}\left(\frac{I_{1}}{I_{2}}\right)+3,9482\left(1-\frac{I_{1}}{I_{2}}\right)-0,0073\left(1-\frac{I_{1}}{I_{2}}\right) S_{i} \\
\operatorname{Ln} V_{2}=1,5085+\frac{-19,7135}{I_{2}}+0,0185\left(S_{i}\right)+1,2242 \operatorname{Ln}\left(B_{2}\right)
\end{array}\right. \\
& \left\{\begin{array}{l}
\operatorname{Ln} B_{2}=\operatorname{Ln} B_{1}\left(\frac{I_{1}}{I_{2}}\right)+3,8202\left(1-\frac{I_{1}}{I_{2}}\right)-0,0047\left(1-\frac{I_{1}}{I_{2}}\right) S_{i} \\
\operatorname{Ln} V_{2}=0,8503+\frac{-3,9334}{I_{2}}+0,0060\left(S_{i}\right)+1,4805 \operatorname{Ln}\left(B_{2}\right)
\end{array}\right. \\
& \left\{\begin{array}{l}
\operatorname{Ln} B_{2}=\operatorname{Ln} B_{1}\left(\frac{I_{1}}{I_{2}}\right)+3,7408\left(1-\frac{I_{1}}{I_{2}}\right) \\
\operatorname{Ln} V_{2}=0,9296+\frac{-8,4116}{I_{2}}+1,5214 \operatorname{Ln}\left(B_{2}\right)
\end{array}\right.
\end{aligned}
$$


Os sistemas de equações simultâneas relacionam os coeficientes aos atributos do povoamento - como idade, índice de local e área basal do povoamento - e os sinais associados a esses coeficientes devem ser analisados com cuidado, pois apresentam significado biológico (CLUTTER et al., 1963). No presente estudo, todos os parâmetros dos modelos ajustados foram significativos $(\mathrm{p}<0,05)$. Entretanto, todos os parâmetros $\alpha_{l}$ dos modelos de Clutter que utilizaram a variável site, apesar de significativos, foram negativos e a aplicação desses modelos pode incorrer em inconsistências nas estimativas de produtividades futuras (CAMPOS e LEITE, 2013). Porém, os resultados da validação mostraram que esses modelos foram precisos para estimar a área basal e o volume.

Alcântara (2012) afirma que a inconsistência nas projeções de volume pelo modelo de Clutter devido a um sinal negativo para o parâmetro associado à variável $\left(1-I_{1} / I_{2}\right) S_{i}$, depende da magnitude dessa estimativa, o que não afetou as estimativas obtidas neste trabalho.

A Tabela 3 traz as estatísticas de precisão dos ajustes dos modelos de Clutter, com e sem a inclusão dos índices de local.

Tabela 3 -Resultado das estatísticas de precisão para o ajuste dos modelos de Clutter variando o $(S)$ obtido pelos quatro métodos estudados: Curva Guia (C.G.); Equação das Diferenças (E.D.); Hammer, Predição de Parâmetros (P.P) e Sem a Variável Site (SS).

\begin{tabular}{|c|c|c|c|c|c|c|c|}
\hline $\begin{array}{c}\text { Variável } \\
\text { Dependente }\end{array}$ & Métodos & $\begin{array}{c}R^{2} \text { ajus } \\
(\%)\end{array}$ & $\begin{array}{c}\text { Correlação } \\
(\%)\end{array}$ & $\begin{array}{c}\text { RQEM( } \\
\left.\text { m }^{3} \cdot \mathbf{h a}^{-1}\right)\end{array}$ & $\begin{array}{c}\text { Erro } \\
\text { padrão( } \\
\left.\text { m }^{3} \cdot \mathbf{h a}^{-1}\right)\end{array}$ & $\begin{array}{l}\text { Coef. de } \\
\text { Var. }(\%)\end{array}$ & BIAS \\
\hline \multirow{5}{*}{$\begin{array}{l}\text { Volume } \\
\left(\mathrm{m}^{3} \cdot \mathrm{ha}^{-1}\right)\end{array}$} & C.G. & 95,62 & 97,79 & 19,673 & 19,690 & 8,480 & $-0,360$ \\
\hline & E.D. & 95,61 & 97,78 & 19,693 & 19,710 & 8,489 & $-0,332$ \\
\hline & Hammer & 95,63 & 97,79 & 19,696 & 19,714 & 8,490 & $-0,427$ \\
\hline & P.P. & 94,77 & 97,35 & 21,400 & 21,418 & 9,224 & $-1,060$ \\
\hline & SS & 94,08 & 97,00 & 22,752 & 22,772 & 9,807 & $-0,221$ \\
\hline \multirow{5}{*}{$\begin{array}{l}\text { Área Basal } \\
\left(\mathrm{m}^{2} \cdot \mathrm{ha}^{-1}\right)\end{array}$} & C.G. & 95,76 & 97,86 & 1,053 & 1,053 & 5,015 & 0,003 \\
\hline & E.D. & 95,76 & 97,86 & 1,053 & 1,053 & 5,013 & 0,004 \\
\hline & Hammer & 95,76 & 97,86 & 1,053 & 1,053 & 5,015 & 0,001 \\
\hline & P.P. & 95,77 & 97,86 & 1,062 & 1,062 & 5,055 & $-0,061$ \\
\hline & SS & 95,82 & 97,89 & 1,046 & 1,046 & 4,978 & $-0,006$ \\
\hline
\end{tabular}


Observa-se que as medidas de precisão obtidas a partir dos dados de ajuste para os quatro métodos apresentaram resultados muito próximos e satisfatórios. Os coeficientes de correlação e determinação ajustados entre as variáveis observada e estimada foram altos. $\mathrm{O}$ Erro Padrão e a RQEM ( $m^{3} \cdot h a^{-1}$ para o volume e $m^{2} \cdot h a^{-1}$ para área basal),assim como o Coeficiente de Variação (\%), foram baixos para as variáveis em análise. O mesmo ocorre para o modelo que não utilizou a variável site. Os resultados do BIAS, foi a medida de precisão que mais diferiu entre os métodos na simulação do volume e área basal. No método da Predição de Parâmetros é possível observar valor ligeiramente superior aos outros métodos.

A Figura 3 apresenta os gráficos obtidos com os modelos de Clutter ajustados. São apresentados os resíduos em termos percentuais entre a área basalobservada e a área basal estimada, alémda correlação entre a área basal observada e a área basal estimada. Observase que, para todos os modelos, tanto a correlação quanto a dispersão dos resíduos percentuais apresentaram comportamentos homogêneos e satisfatórios (GUJARATI, 2006).

Observa-se que o volume estimado pelo modelo de Clutter utilizando os dados separados para o ajuste apresentaram uma distribuição de resíduos percentual adequada, sendo conciso e pouco disperso. A correlação entre os volumes observados e estimados também apresenta-se alta. Pode ser notado a presença de outliers, entretanto, os valores que extrapolaram a tendência geral dos dados, em área basal ou volume em função da idade, não foram eliminados a fim de verificar a capacidade dos modelos em estimar esses valores extremos, visto que não foram advindos de erros de medição. 

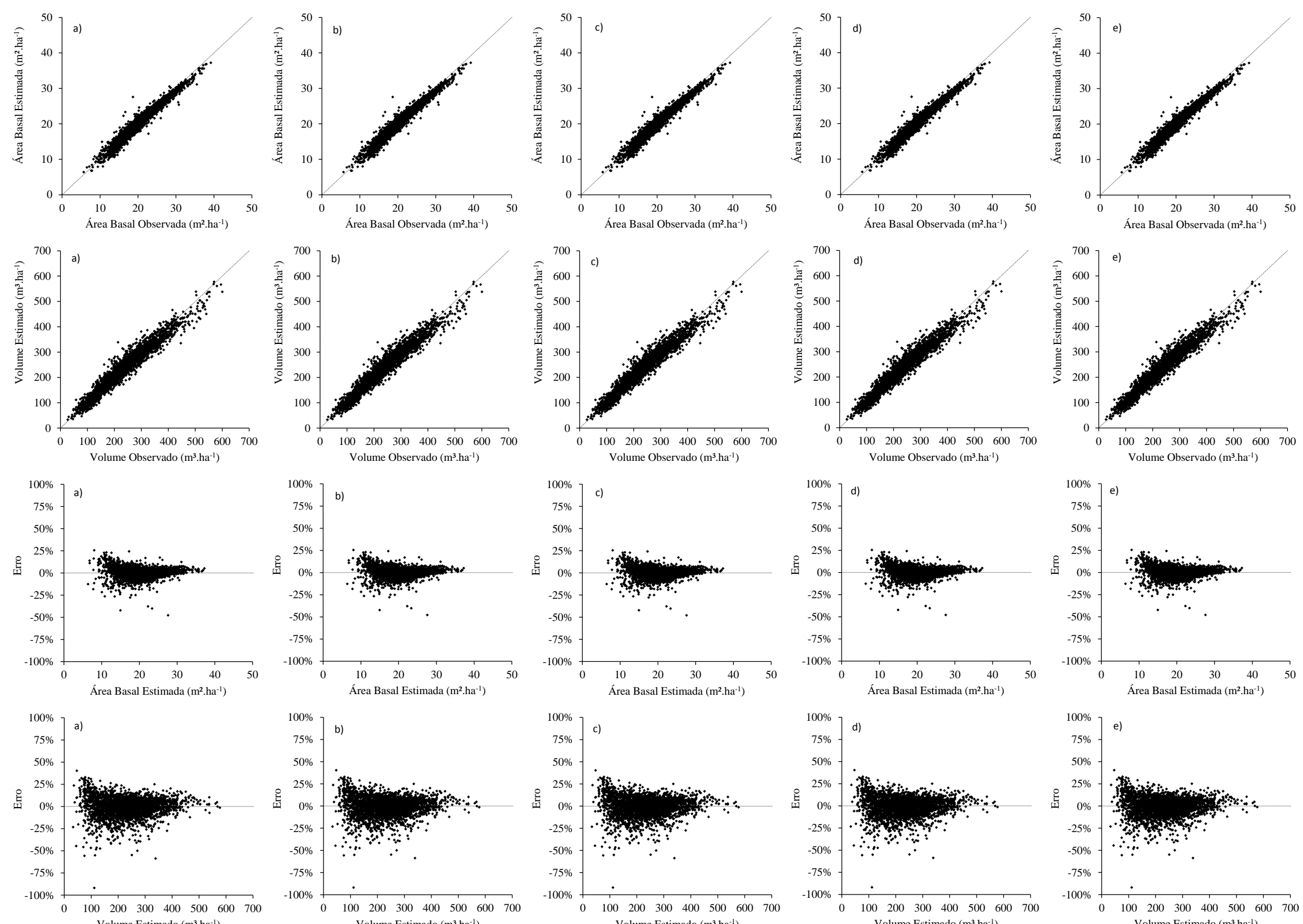

Figura 3 - Análise gráfica das correlações e dos resíduos percentuais obtidos dos modelos de Clutter ajustados utilizando-se a variável site classificada pelos métodos da Curva Guia em a); da Equação das Diferenças em b); de Hammer em c); da Predição de Parâmetros em d) e sem a variável site em e). 
Os resultados de validação dos modelos de Clutter são apresentados adiante. Partindo de uma primeira medição das parcelas de validação, foram estimadas a variável " $S$ "por meio das equações desenvolvidas para os quatro métodos de classificação da capacidade produtiva (utilizando altura dominante e idade atuais de cada parcela). Em seguida, foramestimadas a área basal e volume futuros para cada parcela, ano a ano, até a última idade de medição, na qual, as estimativas futuras já eram conhecidas (idades em que cada parcela foi remedida). As estimativas foram obtidas por meio do modelo de Clutter. Portanto, para cada parcela, foram obtidas as estimativas de produtividade pelos quatro modelos que utilizaram a variável " $S$ " (pelos diferentes métodos de classificação) e pelo modelo que não utilizou a variável " $S$ ". De posse dessas informações, verificou-se quão precisos foram os modelos para as estimativas de produtividade.

A Figura4 apresenta os gráficos obtidos com a validação dos modelos de Clutter gerados a partir do " $S$ " estimado por cada método de classificação e do modelo que não utilizou tal variável. Essa, traz a tendência média de erros para cada classe de produtividade, em cada projeção, para cada método estudado, quando aplicados aos dados de validação.

De maneira geral, as estimativas apresentam aumento nos erros médios nas seguidas projeções. Tal tendência é esperada, visto que os erros são acumulados. Um viés na primeira projeção acarreta em erro cumulativo na segunda projeção e assim sucessivamente.

Segundo Dias (2005) o modelo de Clutter é indicado para predizer o crescimento e a produção para os compartimentos conduzidos sem desbaste. Em sua pesquisa ela afirma que o modelo de Clutter foi considerado eficiente do ponto de vista estatístico e biológico.

Castro et al. (2016) concluiu que o sistema de equações de Clutter com inclusão da variável índice de local $(S)$ foi altamente preciso para a modelagem da distribuição diamétrica de povoamentos de Eucalyptus urophylla $\mathrm{X}$ Eucalyptus grandis. A aplicabilidade do sistema de equações se mostrou bastante eficiente para três prognoses consecutivas. Áreas com baixa capacidade produtiva foram as que obtiveram melhores estimativas, ou seja, menores diferenças significativas, em comparação com os dados observados. 

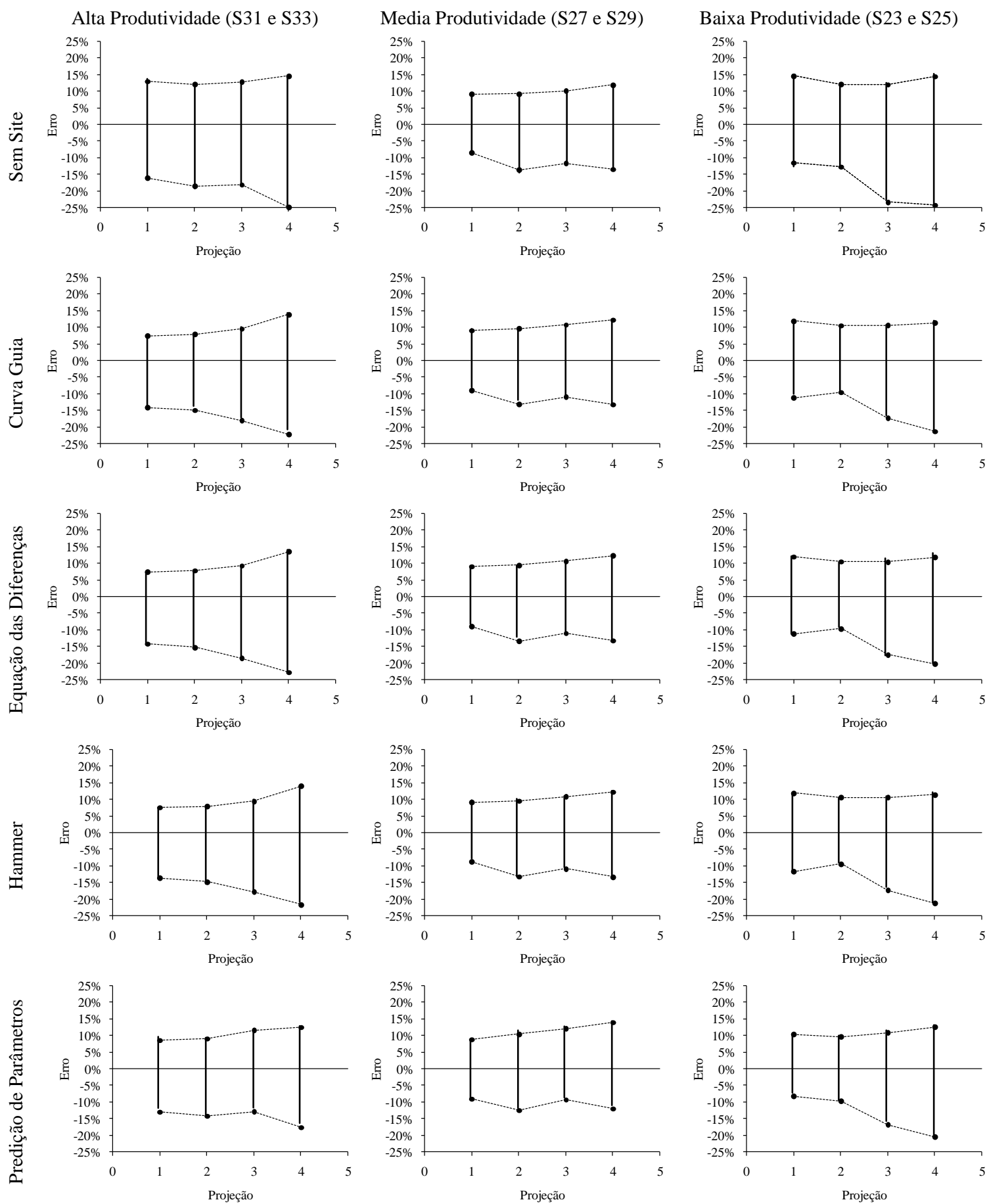

Figura 4 - Tendência média de erros para cada classe de produtividade, por projeção, para cada método estudado, utilizando ou não índice de local, dos dados de validação.

Pode-se observar na Figura 4 que o modelo de Clutter que não utiliza a variável " $S$ " estima bem a produção florestal das classes de média produtividade. No entanto, pode-se observar também que os modelos de Clutter que utilizaram a variável site estimaram com maior precisão a produção florestal das classes de baixa e alta produtividade, apresentando uma amplitude de erro menor que o modelo que não se vale desta variável. 
Os modelos de Clutter conseguiram estimar com precisão as áreas basais e os volumes futuros $\left(B_{2}\right.$ e $\left.V_{2}\right)$ estando satisfatórios e aceitáveis. No entanto, pôde-se observar que houve pequena tendência à superestimação das áreas basais e volumes menores e subestimação das áreas basais e volumes maiores em todos eles. Essa tendência também foi observada por Dias et al. (2005) e Demolinari (2006) e pode ter ocorrido em consequência das mudanças no povoamento, como estagnação do crescimento em área basal, na idade final da projeção. A modelagem é utilizada como suporte à decisão na implantação e no manejo de espécies florestais. Portanto, superestimar ou subestimar o volume de madeira de um empreendimento pode comprometer as tomadas de decisão SALLES, 2012).

Outros trabalhos relataram dados semelhantes, com bom ajuste do modelo de Clutter (1963) aos dados observados em plantios de Pinus (LEITE et al., 2001) e de eucalipto não desbastado (SOARES et al., 2004; DEMOLINARI et al., 2007) e desbastado (DIAS et al., 2005; GÖRGENS et al., 2007).

O que difere os métodos de classificação de local aqui estudados é a complexidade de aplicação. O método da Curva Guia e da Equação das Diferenças são menos complexos que os outros dois. O método de Hammer demanda alguns cuidados e passos a mais do que os dois métodos citados anteriormente. A predição de parâmetros envolve softwares estatísticosmais complexos e demanda maior quantidade de mão de obra, uma vez que parâmetros devem ser gerados para cada parcela separadamente.

Castro et al. (2015) estudando povoamentos não desbastados observou que na validação do modelo de Clutter, aquele utilizando a variável " $S$ ” estimada pelo método das equações das diferenças mostrou-se mais eficiente para realização da prognose do povoamento de Eucalyptusspp. estudado do que o método da curva guia, apresentando melhores estimativas na validação dos modelos.

Este trabalho é uma importante contribuição para a área de manejo florestal e traz informações que validam a importância de utilizar a variável site nos modelos de prognose e produção florestal em nível de povoamento total e ratifica a precisão de quatro métodos de classificação de índice de local. 


\section{CONCLUSÕES}

A classificação da capacidade produtiva por meio de índices de local foi eficiente pelos quatro métodos avaliados, e os modelos de Clutter ajustados, utilizando as variáveis $S$ por todos os métodos, foram precisos;

Os métodos de classificação de local foram eficientes para a projeção do volume e área basal e são indicados para estimativa da produtividade;

Pode-se afirmar que o modelo de Clutter é preciso para estimar a área basal e o volume do povoamento de Eucalyptus spp.estudado, considerando os métodos de índice de local avaliados;

Os métodos de classificação de local diferem entre si somente pela complexidade de aplicação, sendo indicados, portanto, os métodos da curva guia, equação das diferenças ou hammer por possuírem de menor complexidade de aplicação.

Modelos de prognose que não utilizam a variável "S" estimam com precisão a produtividade de locais classificados como de média produtividade, no entanto, apresentam um erro maior quando utilizados em locais classificados como de baixa e alta produtividade. 


\section{REFERENCIAS BIBLIOGRÁFICAS}

ABREU, E. C. R. Modelagem da prognose precoce do volume por classe diamétrica para Eucalyptus grandis. 2000. 70f. Dissertação de Mestrado. Universidade Federal de Lavras, Lavras, MG, 2000.

ALCÂNTARA, A. E. M. de. Alternativas de modelagem para projeção do crescimento de eucalipto em nível de povoamento. 2012. 52f. Dissertação de Mestrado. Universidade Federal de Viçosa, Viçosa, MG, 2012.

ASSMANN, E. Principles of forest yield study. New York: Pergamon Press, 1970. 506p.

BAILEY, R. L.; J. L. CLUTTER. Base-Age Invariant Polymorphic Site Curves. Forest Science, n.20, p.155-159, 1974.

BATES, C. G. Concerning Site. Journal of Forestry, n.16, p.383-388, 1918.

BATISTA, J. L. F.; DO COUTO, H. T. Z. Escolha de modelos matemáticos para a construção de curvas de índice de sítio para florestas Implantadas de Eucalyptus sp. no estado de São Paulo. IPEF, n.32, p.33-42,1986.

BECK, D.E., Polymorphic curves for white pine in the southern Appalachians. USDA, Forest Service ResearchPaper, Asheville, n.80, p.1-89, 1971.

BERTOLUCCI, F.; REZENDE, G.;PENCHEL, R. Produção e utilização de híbridos de eucalipto. Silvicultura, v.51, p.12-16, 1995.

BILA, J. M. Classificação de sítios com base em fatores edáficos para Pinus caribaeavarhondurensisna região de Prata, Minas Gerais. 2010. $77 \mathrm{f}$. Dissertação de Mestrado.Universidade Federal do Paraná, Curitiba, PR, 2010.

BUCKMAN, R.E. Growthandyieldofred pine in Minnesota Washington. DC: USDA, v.1272, p. 1-50, 1962. (TechnicalBulletin, 1272).

BURGER, D. Ordenamento Florestal I. Setor de Ciências Agrárias da Universidade Federal do Paraná. Curitiba. 152p. 1976.

CABACINHA, C.D. Um método para a realização do inventário florestal suprimindo a cubagem rigorosa. 2003. 116f. Dissertação de Mestrado. Universidade Federal de Lavras, Lavras, MG, 2003.

CAJANDER, A. K. The theoryofforesttypes. Acta Forestalia Fênica, Helsinki, v.29, p.1108, 1926.

CAMPOS, J.C.C., LEITE, H.G. Mensuração Florestal: Perguntas e Respostas. 4 ed., atualizada e ampliada. Viçosa, MG, Ed. UFV, 605 p., 2013. 
CASTRO, R. V O.; SOARES, C. P. B.; MARTINS, F. B.; LEITE, H. G. Crescimento e produção de plantios comerciais de eucalipto estimados por duas categorias de modelos. Pesquisa agropecuária brasileira, Brasília, v.48, n.3, p.287-295, 2013.

CASTRO R.V.O., CUNHA A.B., SILVA L.V., LEITE H.G. Modelagem do crescimento e produção para um povoamento de Eucalyptus utilizando dois métodos para quantificação do índice de local. ScientiaForestalis, v.43, n.105, p.83-90, 2015.

CASTRO, R. V. O. et al. Modelagem do crescimento eda produção de povoamentos deEucalyptus em nível de distribuição diamétrica utilizando índice de local. Rev. Árvore, Viçosa, v. 40, n. 1, p. 107-116, Feb. 2016.

CAMPOS, J.C. C. Estudo sobre índice de sitio e tabelas de volume e produção para Pinus elliottiiEngelm no estado de São Paulo-Brasil. Revista Turrialba, Costa Rica. p.1-82, 1970.

CLUTTER, J.L. et al.Manejo de madeira: uma abordagem quantitativa. New York: John Wiley \& Sons, 1983. 333p.

COUTO, H. T. Z. do.; BASTOS, N. L. M. Second rotation Eucalyptus growth curves for the State of São Paulo, IPEF, Piracicaba, n. 34, p.15-21, 1986.

CUNHA NETO, F. R. da; SCOLFORO, J. R. S.; CALEGÁRIO, N.; OLIVEIRA, A. D.; KANEGAE JUNIOR, H. Uso da diferença algébrica para construção de curvas de índice de local para Eucalyptus grandis e Eucalyptus urophylla na região de Luiz Antônio - SP.CERNE, Lavras, MG, v.2, n.2, p.119-141, 1996.

DEBERTIN D.L. Significance tests of regression coefficients: na additional reminder. American Journal of Agricultural Economics, n.57, p.124, 1975.

DEMARS, D. J. Polymorphic Site Index Curves for Noble Fir from Stem Analysis Data. 1969. 41f. Thesis of Master. Oregon State University, Oregon, 1969.

DEMOLINARI, R. A. Crescimento de povoamentos de eucalipto não desbastados. 2006. 72f. Dissertação de Mestrado. Universidade Federal de Viçosa, Viçosa, MG, 2006.

DEMOLINARI, R. de A.; SOARES, C.P.B.; LEITE, H.G.; SOUZA, A.L. de. Crescimento de plantios clonais de eucalipto não desbastados na região de Monte Dourado (PA). Revista Árvore, v.31, n.3, p.503-512, 2007.

DEVAN, J. S.; BURKHART, H. E. Polymorphic Site Index Equations for Loblolly Pine Based on a Segmented Polynomial Differential Model. Forest Science, Bethesda, v.28, n.3, p.544-555, 1982.

DIAS, A. N.; LEITE, H. G.; CAMPOS, J. C. C.; COUTO, L.; CARVAlHO, A. F. Emprego de um modelo de crescimento e produção em povoamentos desbastados de eucalipto. Revista Árvore, v.29, n.5, p.731-739, 2005. 
DIAS, A.N. Um modelo para gerenciamento de plantações de eucalipto submetidas a desbaste. 2005. 135F. Tese de Doutorado. Universidade Federal de Viçosa, Viçosa, MG, 2005.

DOLPH, K. L. Polymorphic site index curves for red fir in California and Southern Oregon. Res. Paper PSW-206. Berkeley. CA: Pacific Southwest Research Station. Forest Service, U.S. Department of Agriculture; 1991, 18p.

DOSSA, D.; SILVA, H.D.; BELlOTE, A.F.J. \& RODIGHERI, H.R. Produção e rentabilidade do eucalipto em empresas florestais. Colombo, Embrapa, out/2003. Disponível em: <http://www.infoteca.cnptia.embrapa.br/handle /doc/307451>. Acesso em: 01 de agosto de 2013.

DRESCHER R., SCHEEREN L.W., MEDEIROS J.G.S., BERTAZO J. Modelos de relação hipsométricas para Tectona grandis L. f. no estado do Mato Grosso. In: $1^{\circ}$ Simpósio Brasileiro de Pós-Graduação em Engenharia Florestal, Santa Maria, Brasil, 2001.

EMERENCIANO, D. B. Avaliação de métodos de prognose da altura aplicados em Pinus elliottii da Floresta Nacional de Capão Bonito - SP. 1981. 70f. Dissertação de Mestrado. Universidade Federal do Paraná, Curitiba, PR,1981.

FERREIRA, C. A. Cultivo do eucalipto: Manejo de plantações para desdobro. In: Embrapa Florestas Sistemas de Produção, Ago./2003. Disponível em: http://sistemasdeproducao.cnptia.embrapa.br/FontesHTML/Eucalipto/CultivodoE ucalipto/08_conducao_para_serraria.htm. Acesso em: 01 de agosto de 2013.

FIGUEIREDO, E. O. Avaliação de modelos pelo método da curva média para construção de curvas de índice de local para TectonagrandisL. f. Rio Branco: Embrapa Acre, 49p, 2005.

FROTHINGHAM, E. H. Height Growth as a Key to Site. Journal of Forestry, n.16, p.754-760, 1918.

GONZÁLEZ, E. R. Transformação genética de Eucalyptus grandis e do híbrido Eucalyptus grandis x Eucalyptus urophyllaviaAgrobacterium. 2002. 93f. Tese de Doutorado, Escola Superior de Agricultura "Luiz de Queiroz", Universidade de São Paulo, Piracicaba, SP, 2002.

GÖRGENS, E., LEITE, H.G., NOGUEIRA, G.S., DIAS, A.N. Tendência de crescimento de povoamento de eucalipto após aplicação de desbaste. Revista Árvore, v.31, n.5, p.879-885, 2007.

GUJARATI, D. N. Econometria Básica. 4.ed. SãoPaulo: Elsevier, 2006. 812 p.

HÄGGLUND, B. Evaluation of forest site productivity. Forestry Abstracts, n.42, p.515$527,1981$.

HAHN, J. T.; CARMEAN, W. H. Lake Statis Index Curves Formulated. USDA, Forest Service, General Technical Report, n.88. 5p. 1982. 
IBÁ, 2015. Relatório IBÁ, 2015. Indústria Brasileira de Árvores. Ano base 2014. Brasília, 2015. 80p. Disponível em: <http://iba.org/images/shared/iba_2015.pdf >. Acesso em: 15 jul. 2016.

IBÁ, 2016. Relatório IBÁ, 2016. Indústria Brasileira de Árvores. Ano base 2015. Brasília, 2016. 100p. Disponível em: <http://iba.org/images/shared/Biblioteca /IBA_RelatorioAnual2016_.pdf>. Acesso em: 15 jul. 2016.

IHS GLOBAL. Eviews 5: quantitative micro software. Version 5. Irvine: IHS Global, 2004.

INSTITUTO DE PESQUISA E ESTUDOS FLORESTAIS - IPEF. Indicações para escolha de espécies de Eucalyptus.Instituto de Pesquisa e Estudos Florestais. Piracicaba, SP. Disponível em: <http://www.ipef.br/identificacao/eucalyptus/indicacoes.asp>. Acessoem: 03 jul.2014.

KALLARACKAL, J.; SOMER, C.K. An ecophysiological evaluation of the suitability of Eucalyptus grandis for planting in the tropics. Forest Ecology and Management, Amsterdan, v.95, p.53-61, 1997.

KÖPPEN, W. Groundriss der klimakunde. Berlin: W. Guyter, 1931, 390p.

LEITE, H.G.; NOGUEIRA, G.S.; MOREIRA, A.M.; LIMA, J.E. de. Um modelo de crescimento e produção para Pinus taeda L. na região Sul do Brasil. Revista Árvore, v.25, p.105-112, 2001.

MACHADO, S. do A. Curvas de índice de sítio para plantações de Pinus taedaL. na região central do Paraná. Floresta, v.11(2), p.4-18, 1980.

MARCOLIN, M. Polimorfismo e tamanho da amostra para construção de curvas de Índice de Sítio para Pinus taedaL.,no segundo planalto Paranaense.1990. 75f.Dissertação de Mestrado. Universidade Federal do Paraná, Curitiba, PR, 1990.

BINOTI, M. L. M.da S., BREDA BINOTI, D. H., GARCIA LEITE, H., Aplicação da função hiperbólica na construção de curvas de índice de local. Revista Árvore [enlinea] 2012, 36 (Julio-Agosto): [Fecha de consulta: 10 de octubre de 2016] Disponibleen:<http://www.redalyc.org/articulo.oa?id=48824769015>ISSN 01006762.

MARTINS, I. S.; PIRES, I. E.; OLIVEIRA, M.C.o de. Divergência genética em progênies de uma população de Eucalyptus camaldulensisDehn. Floresta e Ambiente, Rio de Janeiro, v. 9, n. 1, p. 81-89, jan./dez. 2002. Disponível em: <http://www.floram.org/volumes/vol09-2002/Vo19\%2081A89.pdf>. Acesso em: 21 maio 2016.

MIGUEL, E. P.; IMANÃ-ENCINAS, J.; REZENDE, A. V.; FEREIRA, J. C. S.; AGUIAR, G. P. Classificação de sítio para plantios de Eucalyptus urophylla em Niquelândia, 
Estado de Goiás. ENCICLOPEDIA BIOSFERA, Centro Científico Conhecer Goiânia, v.7, n.12; 2011.

MOSER, J. W.; HALL, O. F. Deriving growth an yield functions for uneven-aged forest stands. Forest Science, Bethesda, v.15, p.183-188, 1969.

PRODAN, M. et al. Mensuração florestal. San José: IICA, 1997. 586p.

ROTH, F. Concerning site. Forestry Quarterly, v.3, n.1, p.3-13, 1916.

ROTH, F. Another Word on Site. Journal of Forestry, v.16, p.749-753, 1918.

SALLES, T. T. et al. Modelo de Clutter na modelagem de crescimento e produção de eucalipto em sistemas de integração lavoura-pecuária-floresta.Pesq. agropec. bras., Brasília, v. 47, n. 2, p. 253-260, Feb. 2012.

SCAVINSKI, Vanessa. Projeção da produção utilizando curvas de sítio anamórficas e polimórficas para plantios de Eucalyptus grandisW. Hill. 2014. 61f. Dissertação de Mestrado. Universidade Estadual do Centro-Oeste, Irati, PR, 2014.

SCHNEIDER, P. R. Introdução ao manejo florestal. $2^{\text {a }}$ ed., Santa Maria, RS, Ed. UFSM, FACOS, 566 p., 2008.

SCHÖNAU, A. P. G.Problems in Using Vegetation or Soil Classification in Determining Site Quality. South African Forestry Journal, v.141, n.1, p.13-18, 1987.

SCHUMACHER, F.X. A new growth curve and its application to timber studies. Journal of Forestry, v.37, p.819-820, 1939.

SCOLFORO, J.R. Biometria Florestal: Métodos para classificação de sítios florestais. Lavras: UFLA/FAEP, 1997. 151p.

SCOLFORO, J.R.S.; MACHADO, S.A. Curvas de índice de sítio para plantações de Pinus elliottii nos Estados do Paraná e Santa Catarina. Floresta, Curitiba, v.18,p.140-58, 1988a.

SEGURA, T. E. S. Avaliação das madeiras de Corymbia citriodora, Corymbia torelliana e seus híbridos visando à produção de celulose kraft branqueada. 2015. 198f. Tese de Doutorado. Escola Superior de Agricultura "Luiz de Queiroz", Universidade de São Paulo, Piracicaba, SP, 2015.

SELLE, G.L. et al. Como classificar sítios florestais através da altura dominante do povoamento. Colombo: Embrapa Florestas, 2008. 46p.

SIIPILEHTO, J. A comparison of two parameter prediction methods for stand structure in Finland. Silva Fennica, v.34, n.4, p.331-349, 2000.

SILVA, J. C. Novos Valores estimulam consumo da madeira de reflorestamento. Visão Agrícola, c.4, n.2, p.112-113. 2005. 
SOARES, C.P.B., LEITE, H.G., OLIVEIRA, M.L.R., CARVALHO, A., Especificação de um modelo de crescimento e produção florestal. Revista Árvore, v.28, n.6, p.831837, 2004.

SPRING, S. N. Notes and Comments: Site and SiteClasses. Journal of Forestry. 476 p, 1917.

SPURR, S.H. Forest Inventory. New York, The Ronald Press Company. 1952.

STAPE, J. L. Utilização de delineamento sistemático tipo leque no estudo de espaçamentos florestais. 1995. 86f. Dissertação de Mestrado. Escola Superior de Agricultura "Luiz de Queiroz", Universidade de São Paulo, Piracicaba, SP, 1995.

STOUT B. B.; SHUMWAY D. L. Site Quality Estimation Using Height and Diameter. Forest Science, Bethesda, v. 28, n. 3, p. 639-645, 1982.

TAQUETTI, M. F. Método da predição de parâmetros em Modelos de crescimento em função do Índice de local. 2014. 23f. Monografia, Universidade Federal de Viçosa, Viçosa, MG, 2014.

TONINI, H. et al. Comparação gráfica entre curvas de índice de local para Pinus elliottii e Pinus taeda desenvolvidas no Sul do Brasil.Ciência Florestal, v.12, n.1,p.143152, 2002.

TORRES, R. J. M. Curvas de índice de sítios de forma y escala variables em investigación forestal. Agrociencia, v.35, n.1, p.87-98, 2001.

VAN LAAR, A.; AKÇA, A. Forest Mensuration. Gottingen, Germany: Cuvillier Verlag, 1997, $418 \mathrm{p}$.

VANCLAY, J. K. Modelling Forest Growth and Yield: Applications to Mixed Tropical Forests. Wallingford: CAB International. 1994. 312p.

VARGAS-LARRETA, B. et al. Construcción de curvas dinámicas de índice de local para Pinus cooperi Blanco. Revista Fitotecnia Mexicana, v.33, n.4, p.343-351, 2010.

VITAL, M. H. F. Impacto ambiental de florestas de eucalipto.Revista do BNDES, v. 14, n. 28, p. 235-276, dez. 2007. 